\title{
As espécies de Croton L. sect. Cyclostigma Griseb. e Croton L. sect. Luntia (Raf.) G. L. Webster subsect. Matourenses G. L. Webster (Euphorbiaceae s.s.) ocorrentes na Amazônia brasileira
}

\author{
Luiz Alberto Cavalcante GUIMARÁES ${ }^{1}$, Ricardo de S. SECCO²
}

\section{RESUMO}

Como parte de uma revisão taxonômica das espécies de Croton L. na Amazônia brasileira, estudou-se as seguintes espécies de Croton sect. Cyclostigma Griseb. e Croton sect. Luntia (Raf.) G. L. Webster subsect. Matourenses G. L. Webster: Croton urucurana Baill., C. draconoides Müll. Arg., C. trombetensis R. Secco, P. E. Berry \& N.A. Rosa, C. sampatik Müll. Arg., C. palanostigma Kl., C. pullei Lanj. e C. matourensis Aubl. O estudo foi baseado em trabalho de campo realizado nos Estados do Pará e Maranhão, e em material depositado nos herbários IAN, INPA, MG e RB, incluindo tipos. Algumas dessas espécies, como C. urucurana, C. draconoides, C. palanostigma e C. sampatik, são frequentemente encontradas nos herbários com identificações equivocadas. São discutidas a posição taxonômica das espécies nas seçóes e suas afinidades, e uma chave dicotômica e ilustraçóes foram elaboradas para um melhor entendimento dos táxons.

PALAVRAS-CHAVE: Euphorbiaceae, Croton na Amazônia brasileira, Taxonomia vegetal.

\section{Species of Croton L. sect. Cyclostigma Griseb. and Croton L. sect. Luntia (Raf.) G. L. Webster subsect. Matourenses G. L. Webster (Euphorbiaceae s.s.) occuring within Brazilian Amazon}

\begin{abstract}
As part of a taxonomic revision of Brazilian Amazonia species of Croton L., the following species of Croton sect. Cyclostigma Griseb. and Croton sect. Luntia (Raf.) G. L. Webster subsect. Matourenses G. L. Webster were studied: Croton urucurana Baill., C. draconoides Müll. Arg., C. trombetensis R. Secco, P. E. Berry \& N.A. Rosa, C. sampatik Müll. Arg., C. palanostigma Kl., C. pullei Lanj. and C. matourensis Aubl. This study was based on field work in the States of Pará and Maranhão, and material deposited in herbaria IAN, INPA, MG e RB, including the types. Some of the species, such as C. urucurana, C. draconoides, C. palanostigma, and C. sampatik, are frequently found with misidentification in herbaria. The taxonomic position of the species within sections and their affinities are discussed, and a dychotomic key and illustrations were elaborated for a better understanding of the taxa.
\end{abstract}

KEYWORDS: Euphorbiaceae, Croton in Brazilian Amazonia, Plant Taxonomy.

${ }_{1}^{1}$ Museu Paraense Emilio Goeldi, curso de pós-graduação em Botânica Tropical UFRA/MPEG, Belém, PA, Brasil; E-mail: lacg2775@yahoo.com.br

${ }^{2}$ Museu Paraense Emilio Goeldi, Av. Magalhães Barata, 376, CEP 66040-170, Belém, PA, Brasil, pesquisador; E-mail: rsecco@museu-goeldi.br 


\section{INTRODUÇÃO}

Segundo Webster (1994) e Govaerts et al. (2000) Croton L. é um dos maiores gêneros das Euphorbiaceae, com cerca de 1.200 espécies (Govaerts et al. 2000), a maioria distribuída nas Antilhas e América do Sul, e algumas na América do Norte, África e Madagascar (Webster 1993). São árvores, arbustos, ervas e lianas, geralmente monóicas, algumas vezes dióicas, com tricomas de tipos variados, tais como estrelados, escamiformes (lepidotos), estrelado-lepidotos, lepidotoestrelados, estrelado-dendríticos, simples, entre outros, sendo que, de acordo com Secco (2004; 2009) e Secco et al. (2005), algumas espécies apresentam tricomas do tipo simples, viloso, que podem estar nas sépalas, pétalas ou nos estames. Em geral as inflorescências apresentam as flores pistiladas na base e as estaminadas no ápice, os estames dobrados no botão floral e as pétalas das flores pistiladas reduzidas ou ausentes.

Desde o tratamento de Müller (1873), na Flora brasiliensis, as espécies brasileiras não foram totalmente revisadas e diversos táxons novos vêm sendo propostos (Secco 2004; 2009; Secco et al. 2005)), o que torna confusa a taxonomia de Croton. Alguns tratamentos recentes sobre as espécies da América do Sul, como os de Cordeiro (1992), Secco (1992), Murilo (1999), Webster et al. (1999) e Secco (2008) ainda são insuficientes para que se possa avaliar precisamente os limites específicos em Croton L. Nos herbários amazônicos (IAN, INPA e MG) há uma grande quantidade de espécimes mal identificados ou indeterminados, o que indica o precário conhecimento taxonômico do gênero e dificulta o uso destes acervos como material de referência.

De acordo com estudos de Secco (1992) e Secco (2008), até o momento já foram detectadas cerca de 42 espécies amazônicas para o gênero, distribuídas nos seguintes estados: Roraima, Amapá, Amazonas, Acre, Pará, Maranhão e Rondônia.

De acordo com Webster (1993), em Croton sect. Cyclostigma ocorrem várias espécies da América do Norte, América do Sul, África e Madagascar. Na Amazônia brasileira estấo representadas apenas $C$. draconoides Müll. Arg., $C$. urucurana Baill., C. sampatik Müll. Arg., C. palanostigma Klotzsch, C. pullei Lanj. e C. trombetensis R. Secco; P. E. Berry \& N. A. Rosa. O mesmo autor informa que em Croton sect. Luntia ocorrem vários representantes neotropicais, mas em Croton sect. Luntia subsect. Matourenses ocorrem apenas C. matourensis Aublet e C. lanjowensis Jabl., esta última considerada como um sinônimo da primeira (Secco 2008).

Este trabalho tem como objetivo estudar as características morfológicas de sete espécies do gênero, pertencentes a Croton sect. Cyclostigma (Croton trombetensis R. Secco, P.E. Bery \& N.A. Rosa, Croton urucurana Baill., Croton draconoides Müll. Arg., Croton palanostigma Klotzsch, Croton pullei Lanj. e Croton sampatik Müll. Arg.) e Croton sect. Luntia subsect.
Matourenses (Croton matourensis Aubl.), considerando-se que algumas espécies de tais seçóes são próximas entre si, como Croton urucurana Baill, Croton draconoides Müll. Arg. e Croton sampatik Müll. Arg., e muitas vezes são identificadas erroneamente nos herbários, devido apresentarem semelhanças morfológicas.

\section{MATERIAL E MÉTODOS}

O material de estudo foi baseado principalmente em amostras herborizadas, depositadas nos herbários da EMBRAPA Amazônia oriental (Herbário IAN), do Instituto Nacional de Pesquisas da Amazônia (INPA), do Museu Paraense Emílio Goeldi (MG) e do Jardim Botânico do Rio de Janeiro (RB), sendo que coletas adicionais foram feitas pelo coautor nos estados do Pará e Maranhão. As siglas dos herbários estáo de acordo com o Index Herbariorum (Holmgren et al. 1990). A identificação das espécies foi feita pelos métodos clássicos da taxonomia vegetal, tais como dissecção, mensuração e ilustração das partes vegetativas e reprodutivas, seguindo-se comparação com o material herborizado existente nos herbários IAN, INPA, MG e RB, bem como por meio de análise de alguns tipos, diagnoses e descriçóes existentes na literatura. Todo o material foi examinado com o auxílio de estéreo-microscópio ZEISS, acoplado à câmara clara. A ordem de descrição das espécies está de acordo com a sequência de organização das tribos proposta por Webster (1993).

\section{RESULTADOS E DISCUSSÃO}

\section{CARACTERIZAÇÃO DAS SEÇÕES E SUBSEÇÕES ESTUDADAS}

Webster (1993) propôs várias seçóes para Croton, baseando-se no maior número possível de características morfológicas, incluindo tipos de hábito, indumento, folhas, inflorescências, flores e frutos, bem como nos caracteres de monoicismo e diocismo das plantas, na tentativa de melhor organizar a taxonomia do gênero.

Das espécies aqui tratadas, apenas Croton matourensis pertence a Croton sect. Luntia subsect. Matourenses G. L. Webster que, de acordo com Webster (1993), se caracteriza pelas folhas geralmente ferrugíneas na face abaxial, inflorescências estaminadas ou bissexuadas, sem a presença de cimas na base e flores pistiladas longo-pediceladas.

Croton draconoides, C. sampatik, C. pullei, C. palanostigma, C. trombetensis e $C$. urucurana pertencem a Croton sect. Cyclostigma Griseb., alojadas nas seguintes subseçôes, caracterizadas de acordo com Webster (1993):

I. Croton sect. Cyclostigma subsect. Cyclostigma: Croton. urucurana e $C$. trombetensis, sendo esta última de acordo com Secco et al. (2001). Esta seção também comporta C. draconoides, apesar de náo ter sido citada por Webster 
(1993). Esta subseção engloba as espécies que se caracterizam pelas folhas peninérveas ou palmatinérveas, com margem denticulada, denso indumento de tricomas estrelados na face abaxial, estames 15-65, cálice da flor pistilada não reduplicadovalvado e estiletes bífidos.

II. Croton sect. Cyclostigma subsect. Sampatik: Croton sampatik. Esta subseção engloba espécies com folhas peninérveas, esparsamente pubescente-estreladas, com a margem crenada, estames 10 a 20, flores pistiladas longopediceladas, sépalas das flores pistiladas não reduplicadovalvadas e estiletes bífidos.

III. Croton sect. Cyclostigma subsect. Palanostigma: Croton palanostigma e C. pullei. Esta subseção apresenta geralmente espécies com folhas palmatinérveas e com denso indumento de tricomas estrelados na face abaxial, estames 10-100, flores pistiladas pediceladas, com sépalas mais ou menos reduplicado-valvadas e estiletes multífidos.

\section{ASPECTOS MORFOLÓGICOS}

\section{HÁBITO}

Os representantes das Euphorbiaceae podem ser arbustos, arvoretas, árvores, ervas ou lianas lenhosas. Todos esses tipos de hábito são compartilhados com as espécies de Croton. As espécies amazônicas analisadas incluem-se em formaçóes florestais e são árvores, com exceção de C. pullei, que possui o hábito variando de lianescente a arvoreta escandente. Croton matourensis e $C$. draconoides podem ser encontradas também como arbustos, enquanto $C$. palanostigma e C. urucurana como arvoretas.

\section{INDUMENTO}

Nas sete espécies de Croton L. analisadas observou-se a presença de tricomas tanto nos órgáos vegetativos (ramos e folhas) como nos reprodutivos (inflorescências, flores e frutos). Nos ramos todas apresentaram tricomas estrelados ou lepidotos (escamiformes). Em C. draconoides, o indumento é denso, tomentoso, com tricomas estrelados, enquanto em $C$. pullei o indumento é pubescente. Croton matourensis apresenta tricoma do tipo lepidoto, de tonalidade ferrugínea, ou também raros tricomas estrelados-dendríticos; em C. matourensis e C. palanostigma o indumento é piloso, sendo que em $C$. urucurana é tomentoso, quando jovem, é pubérulo quando adulta, alvacento a ferrugíneo.

Nas folhas observou-se tricomas estrelados sobre a superfície de seis das espécies analisadas neste trabalho, sendo Croton matourensis a única a apresentar denso indumento de tricomas lepidotos, possuindo também glândulas capitadas na face abaxial, o que lhe confere um aspecto metálico-ferrugíneo, dourado. Em Croton palanostigma e C. pullei os tricomas variam de estrelados a estrelado-lepidotos.
Croton draconoides, C. sampatik, C. urucurana e $C$. trombetensis possuem denso indumento com tricomas do tipo estrelado na raque das inflorescências. Nas flores estaminadas, C. matourensis, C. trombetensis, C. draconoides, C. palanostigma e $C$. pullei apresentam os pedicelos com indumento piloso, enquanto em C. sampatik o pedicelo é pubescente. Nas flores pistiladas, todas as espécies possuem pedicelos com tricomas: em C. matourensis são lepidotos, em C. palanostigma estreladolepidotos e em C. pullei, C. draconoides e C. trombetensis, estrelados. $\mathrm{O}$ cálice das flores estaminadas possui tricomas lepidotos externamente em C. matourensis; tricomas estreladolepidotos em C. palanostigma e $C$. pullei, e estrelados em $C$. sampatik, C. draconoides, C. urucurana e C. trombetensis, sendo que este último exibe tricomas simples, vilosos, nas margens. Apenas $C$. draconoides possui cálice com denso indumento de tricomas simples, vilosos, na margem e internamente.

No cálice das flores pistiladas, todas as espécies estudadas possuem tricomas externamente. Em Croton matourensis, $C$. palanostigma e C. pullei o indumento é piloso; denso-piloso com tricomas lepidotos em C. matourensis; indumento de tricomas estrelado-lepidotos, com tricomas simples, vilosos, nas margens internamente, em $C$. palanostigma. Nas demais espécies, o indumento é de tricomas estrelados. Em C. pullei os tricomas são de cor ferrugínea e prateada tanto externamente como internamente. Internamente ao cálice, encontram-se tricomas simples, vilosos em C. matourensis e C. draconoides, sendo que em $C$. draconoides os tricomas simples, vilosos estão na parte apical e na margem das sépalas.

Em todas as espécies analisadas, as pétalas das flores estaminadas apresentam tricomas simples, vilosos. Croton urucurana, C. sampatik, C. trombetensis e $C$. draconoides possuem pétalas glabras externamente, e tricomas simples, vilosos na margem, internamente. Em $C$. draconoides e $C$. sampatik os tricomas simples, vilosos estão concentrados na margem e parte apical, respectivamente. Croton palanostigma possui tricomas simples, vilosos externamente na margem e internamente na parte apical. Em Croton pullei ocorrem tricomas estrelados esparsos externamente, podendo ocorrer também pétalas glabras, com tricomas simples, vilosos e margem ciliada internamente. Em C. matourensis, os tricomas simples, vilosos ocorrem apenas nas margens, principalmente na metade basal.

Em relação às flores pistiladas, apenas $C$. trombetensis possui pétalas com tricomas simples, vilosos internamente. Em C. draconoides ocorre um denso indumento de tricomas estrelados a estrelados-dendríticos nas pétalas.

Nos estames de $C$. draconoides, $C$. sampatike $C$. trombetensis os filetes são glabros, estando assentados em tufos de tricomas simples, vilosos. Nas demais espécies, os filetes apresentam tricomas simples, vilosos por toda a extensão, com exceção de C. urucurana, em que estáo localizados apenas na base do 
filete. O ovário de C. matourensis é denso-piloso, com tricomas lepidotos; nas outras espécies, o ovário apresenta tricomas estrelados. Croton palanostigma apresenta tricomas estreladodendríticos e estrelado-porrectos; $C$. pullei e $C$. trombetensis têm tricomas estrelados, sendo que em $C$. pullei estes são de cor ferrugínea. O estilete tem indumento denso-piloso em $C$. matourensis e $C$. pullei, e com tricomas do tipo lepidoto, de cor ferrugínea, e estrelado, respectivamente.

\section{FOLHAS}

As espécies de Croton L. aqui estudadas apresentam as folhas com filotaxia alterna. A forma cordada está presente em C. palanostigma, C. pullei e C. trombetensis. Em Croton urucurana e $C$. draconoides, as folhas podem ser cordadas a oval-lanceoladas e oval-elípticas, respectivamente. Em Croton sampatik variam de oval a oval-lanceoladas. A base das folhas é cordada na maioria das espécies: em $C$. palanostigma varia de cordada a aguda ou raro levemente cuneada, e em $C$. pullei pode ser cordada, cordado-auriculada ou arredondada, às vezes reta. Croton matourensis destaca-se das demais por ser a única a apresentar a base obtusa. O tipo de ápice dominante é acuminado, podendo ser também do tipo agudo, em C. draconoides, C. palanostigma e C. urucurana. Croton trombetensis é a única exceção, apresentando o ápice caudado. As folhas apresentam margem inteira, podendo ser suavemente ondulada (Croton draconoides e Croton palanostigma) ou espaçadamente denteada (Croton sampatik). Em Croton trombetensis a margem é denteada. A folha é peninérvea, podendo ser trinervada a partir da base, com um par de glândulas na base do limbo ou no ápice do pecíolo. As nervuras são geralmente visíveis em ambas as faces.

\section{INFLORESCÊNCIAS}

De acordo com Secco (2005), em Croton as inflorescências são geralmente bissexuadas, dispostas em racemo ou tirsoracemiforme (ex. Croton palanostigma, C. trombetensis), ou racemo digitado/umbeliforme, com as flores pistiladas geralmente na base, às vezes reunidas com algumas estaminadas, e as estaminadas geralmente agrupadas em cimas, fascículos ou glomérulos em maior quantidade, no restante da raque. Também podem ser encontradas, raramente, inflorescências unissexuadas, mas na mesma planta, do tipo racemosa.

Em C. draconoides, C. urucurana, C. pullei e C. sampatik as inflorescências são racemosas, com flores dispostas em fascículos; em C. urucurana as flores estão dispostas em glomérulos. Em C. pullei, a inflorescência às vezes é geminada, acompanhada de outras menores com maior número de flores pistiladas. Croton matourensis pode apresentar uma das duas formas de inflorescência: bissexuada, com flores pistiladas na base e estaminadas no restante da raque, ou mais raramente unissexuada, com flores estaminadas. Em C. palanostigma e
C. trombetensis a inflorescência é do tipo tirso-racemiforme (Secco et al. 2001), sendo que em C. trombetensis as flores estâo agrupadas em fascículos.

\section{FLORES}

Nas espécies de Croton analisadas, as flores pistiladas encontram-se geralmente na base da inflorescência, podendo estender-se por toda a raque junto com as flores estaminadas, que ficam na parte distal, agrupadas em fascículos ou glomérulos. Todas são pediceladas, com os estames variando de 10-16, dobrados no botão floral. As pétalas são em número de 5 , nas flores estaminadas, podendo ser lanceoladas, lanceoladoespatuladas, elípticas ou elíptico-ovais; nas flores pistiladas, as pétalas podem estar ausentes (C. palanostigma), reduzidas ou obsoletas. O cálice é 5-lobado, presente em todas as espécies, podendo ter lobos sagitados, lanceolados ou elípticos. O ovário geralmente é subgloboso, com 3 lóculos, 3 estiletes, que se dividem uma ou mais vezes (bífidos ou multífidos).

\section{FRUTOS}

Barroso et al. (1999) informam que em Croton., além do fruto esquizocárpico, há outro tipo de fruto, que foi classificado como cápsula loculicida. Nas espécies analisadas, observou-se frutos do tipo esquizocarpáceo, com três mericarpos, pubescentes a pilosos, com indumento de tricomas estrelados, estrelado-porrectos, estrelado-lepidotos ou lepidotos, com cálice persistente ou não, e sementes carunculadas ou ecarunculadas (C. sampatik), pintalgadas.

\section{USOS}

Segundo Schultes (1987), Croton L. é um dos mais fascinantes gêneros de Euphorbiaceae do ponto de vista da etnobotânica, apresentando inúmeras espécies úteis (algumas medicinais) no Novo Mundo, sendo que daquelas encontradas no Brasil cita como exemplos C. humilis L. (Brasil), utilizada para distúrbios urinários; C. cajucara Benth., como antifebril, e C. palanostigma Kl. (Brasil), cuja resina é usada para úlceras.

$\mathrm{Na}$ Amazônia, segundo o conhecimento tradicional, além de C. palanostigma, são utilizadas C. lechleri Müll. Arg., um excelente cicatrizante usado no Peru, Equador e Bolívia, e $C$. draconoides Müll. Arg., encontrada no Peru, Brasil (Roraima, Amazonas, Pará, Maranhão e Rondônia) e Guiana Francesa, com efeito provavelmente similar ao de C. lechleri Müll. Arg., da qual é muito próxima. Além dessas, propaga-se o uso de C. cajucara ("sacaca"), para males do fígado e como emagrecedor, embora tais propriedades sejam contestadas por alguns farmacêuticos.

Pieters (1998) cita a utilização de várias espécies de Croton conhecidas na América do Sul como sangre de grado (sangue-de-dragão), como seguem: C. lechleri Müll. Arg. (para cicatrizar feridas e curar reumatismo, no Peru), C. palanostigma Klotzsch (a resina é um agente antitumoral), C. urucurana 
Baill. e C. draconoides Müll. Arg., ambas para curar feridas, entre outras.

De acordo com Grenand et al. (2004), a casca de Croton matourensis Aublet, macerada em água fresca, é utilizada pelos índios Palikur, na Guiana Francesa, contra diarreia.

\section{TRATAMENTO TAXONÔMICO}

\section{EUPHORBIACEAE ADR. JUSSIEU}

Ervas, arbustos, árvores ou lianas, látex ou resina presentes. Folhas alternas, às vezes opostas ou raramente verticiladas, simples ou compostas (Hevea Aubl.), inteiras ou palmado-lobadas, com estípulas persistentes ou decíduas, margem geralmente inteira, com nectários extraflorais em geral presentes. Inflorescências variadas do tipo racemosa, racemo-espiciforme, tirso-racemiforme, panículas, dicásios e pseudantos, axilares, terminais ou caulifloras. Flores diclinas, actinomorfas, raramente zigomorfas, aclamídeas ou monoclamídeas, raro diclamídeas, (1-)3-6(-8)-meras, disco nectarífero frequentemente presente. Cálice gamossépalo ou dialissépalo, corola gamo ou dialipétala, 3-6 pétalas, prefloração valvar ou imbricada; estames (1-)3-50, hipóginos, com filetes livres ou concrescidos, anteras biloculares, introrsas ou extrorsas, gineceu sincárpico, ovário súpero, geralmente 3-4-carpelar, 2-5 locular, óvulos 1 a 2 por lóculo, placentação axilar, estiletes livres ou concrescidos, inteiros ou ramificados. Frutos esquizocarpáceos ou capsulídeos, raramente bagas ou drupas, mericarpos geralmente 3-5; sementes carunculadas ou ecarunculadas.

\section{CROTON L., SP. PL. 2: 1004-1005. 1753}

Árvores, arbustos, ervas ou lianas, monóicos, mais raramente dióicos. Ramos geralmente com resina, glabros ou com indumento de tricomas simples, estrelados ou lepidotos (escamiformes). Folhas alternas, peninérveas ou palmatinérveas, pecíolos geralmente com glândulas no ápice; estípulas presentes, às vezes inconspícuas ou ausentes; limbo inteiro ou lobado, margem inteira ou às vezes serrilhada ou denteada. Inflorescências racemosas ou racemos espiciformes, às vezes em tirso ou panículas, terminais ou axilares, geralmente bissexuadas, com as flores pistiladas na base, geralmente solitárias, em menor quantidade, às vezes reunidas com as estaminadas, as estaminadas geralmente agrupadas em cimas, fascículos ou glomérulos, em maior quantidade, no restante da raque; inflorescências unissexuadas mais raras, geralmente com apenas flores estaminadas agrupadas na raque. Flores estaminadas diclamídeas com cálice 4-6 lobado, lobos valvares, ou cálice livre, pétalas geralmente 5 (raramente ausentes); estames livres, filamentos dobrados no botáo; flores pistiladas mono ou diclamídeas, geralmente com cálice 5-7 lobado, lobos valvares ou cálice livre, pétalas 5, geralmente reduzidas ou ausentes; gineceu sincárpico, 3-carpelar, ovário 3-locular (1-locular em Croton sect. Crotonopsis), óvulo 1 por lóculo, estiletes geralmente livres ou unidos na base, bífidos ou multífidos. Frutos esquizocarpáceos ou capsulídeos; sementes carunculadas ou ecarunculadas.

\section{ESPÉCIE-TIPO. CROTON AROMATICUS L.}

Gênero bastante complexo, necessitando de uma criteriosa revisão, especialmente das espécies que ocorrem na Amazônia. A maioria das espécies apresenta a inflorescência com as flores pistiladas na base, geralmente solitárias, ou em díades ou tríades, e as estaminadas agrupadas no restante da raque, os estames dobrados no botão floral, e as flores pistiladas com pétalas geralmente reduzidas, obsoletas ou ausentes. Está representado por cerca de 1.200 espécies, com a maioria ocorrendo nas Américas (Webster 1993).

As espécies aqui analisadas apresentam hábito arbóreo, arbustivo ou lianescente, indumento constituído por tricomas estrelados ou lepidotos (escamosos), folhas inteiras ou raramente lobadas (ex. C. palanostigma), inflorescências terminais racemosas ou tirso-racemiformes, flores estaminadas com 5 pétalas, sendo reduzidas, obsoletas ou ausentes nas flores pistiladas; cálice 5-lobado, gineceu 3-carpelar e ovário com um óvulo por lóculo.

\section{CHAVE PARA IDENTIFICAÇÃO DAS ESPÉCIES DE CROTON L. SECT. CYCLOSTIGMA E CROTON SECT. LUNTIA SUBSECT. MATOURENSES OCORRENTES NA AMAZÔNIA BRASILEIRA.}

1. Folhas com tricomas lepidotos, face abaxial com aspecto metálico-ferrugíneo, dourado; cálice da flor pistilada fendido apenas no ápice, lobos reduzidos 7. C. matourensis

1'. Folhas com tricomas estrelados, face abaxial sem essa característica; cálice da flor pistilada fendido abaixo do ápice, às vezes quase livre, lobos expandidos .....................................

2. Folhas com margem denteada ....................................... 3

3. Folhas com ápice caudado, face adaxial velutina ao toque; inflorescência $40-60 \mathrm{~cm}$; estames 16 ...3. C. trombetensis

3. Folhas com ápice acuminado, face adaxial pubescente (tricomas concentrados nas nervuras); inflorescência 12-20 $\mathrm{cm}$; estames 11-12

4. C. sampatik

2'.Folhas com margem inteira a discretamente ondulada .........4

4. Liana; cálice da flor pistilada com os lobos irregulares, assimétricos, reduplicados (com ondulaçôes) 6. C. pullei

4. Arvoretas a árvores, raro arbustos; cálice da flor pistilada com os lobos simétricos, não reduplicados (sem ondulaçôes) $\ldots . . .5$

5. Cálice das flores estaminadas e pistiladas com tricomas estrelado-lepidotos; estames 10-11 5. C. palanostigma

5'. Cálice das flores estaminadas e pistiladas com tricomas tipicamente estrelados; estames 14-20

6. Face abaxial das folhas tomentosa, alvacenta, ferrugínea nas nervuras, com aspecto pulverulento; flores estaminadas com pedicelo 3-3,5 mm compr., lobos do cálice glabros 
internamente; ovário hirsuto, tricomas estrelados de braços longos, ramos dos estiletes unidos até cerca da metade ..........1. C. urucurana

6'. Face abaxial das folhas denso-velutina, não alvacenta, inteiramente ferrugínea, sem aspecto pulverulento flores estaminadas com pedicelo 8-9 mm compr., lobos do cálice pubescentes internamente; ovário piloso, tricomas estrelados de braços curtos, ramos dos estiletes unidos apenas na base. 2. C. draconoides

\section{DESCRIÇÃO DAS ESPÉCIES}

1. Croton urucurana Baill., Adansonia 4: 335.1864. Tipo. Brasil. Claussen, n. 770- Weddell. (G!, K!; foto do tipo, A!, IAN!). s/d. - Prov. Rio de Janeiro et Minas-Geraes. Figura 1.

Arvoretas a árvores, 4-15 m alt. Ramos jovens tomentosos, adultos pubérulos, indumento alvacento a ferrugíneo, tricomas estrelados; resina avermelhada, cor de sangue. Folhas 7,5-13,5 $\mathrm{cm} \times 5-10,5 \mathrm{~cm}$, palmatinérveas, cordadas a oval-lanceoladas, membranáceas; face adaxial ferrugíneo-tomentosa nas folhas jovens, pubérula nas adultas, face abaxial tomentosa, tricomas estrelados, alvacenta, ferrugínea nas nervuras, margem inteira, base cordada a auriculada, ápice acuminado; pecíolo 6-9 cm compr., tomentoso, tricomas estrelados, com 2-4 glândulas pateliformes no ápice; estípulas 2 , basais, $1,0-1,5 \mathrm{~cm}$ compr., foliáceas. Inflorescência racemosa, terminal e axilar, 10-25 $\mathrm{cm}$ compr., raque tomentosa, tricomas estrelados, flores estaminadas e pistiladas reunidas em fascículos, ou estaminadas acima das pistiladas. Flores estaminadas com pedicelo 3-3,5 $\mathrm{mm}$ compr., pubescente, tricomas estrelados, cálice 5-lobado, lobos ovais a oval-lanceolados, 2-2,5 mm compr., ciliados na margem, pilosos externamente, tricomas estrelados, glabros internamente, pétalas 5, elíptico-lanceoladas, 2,5-3 mm compr., glabras externamente, com tricomas simples, vilosos apenas nas margens e na base internamente, estames 14-16, ca. 3,5-4,5 mm. compr., com filetes com tricomas simples, vilosos na base, inseridos em receptáculo, com tricomas simples, vilosos, disco 5-segmentado. Flores pistiladas com pedicelo 2 mm compr., pubescente, tricomas estrelados, cálice 5-lobado, unido apenas na base, quase livre, lobos regulares, simétricos, não reduplicados, elíptico-ovais a espatulados, $2-2,5 \mathrm{~mm}$ compr., pilosos externamente, tricomas estrelados, glabros internamente, pétalas 5, reduzidas, ca. 1-1,2 mm compr., glandulosas no ápice, ovário 2-2,5 mm diâm., subgloboso, hirsuto, denso indumento de tricomas estrelado-porrectos, de braços longos, estiletes 3 , os ramos unidos até cerca da metade, bífidos no ápice. bífidos da metade ao ápice. Frutos 5-6,5 mm diâm., globosos, levemente muricados, pubescentes, tricomas estrelados, mericarpos pouco acentuados, cálice persistente na maturação; sementes 3,5-4 mm compr., castanhas, estriadas na face dorsal, verruculosas na ventral, carunculadas.

Distribuição. Brasil (Acre, Maranhão, Bahia, Mato Grosso, Goiás, Minas Gerais, Espírito Santo, Rio de Janeiro, São Paulo, Paraná, Santa Catarina e Rio Grande do Sul), Bolívia,
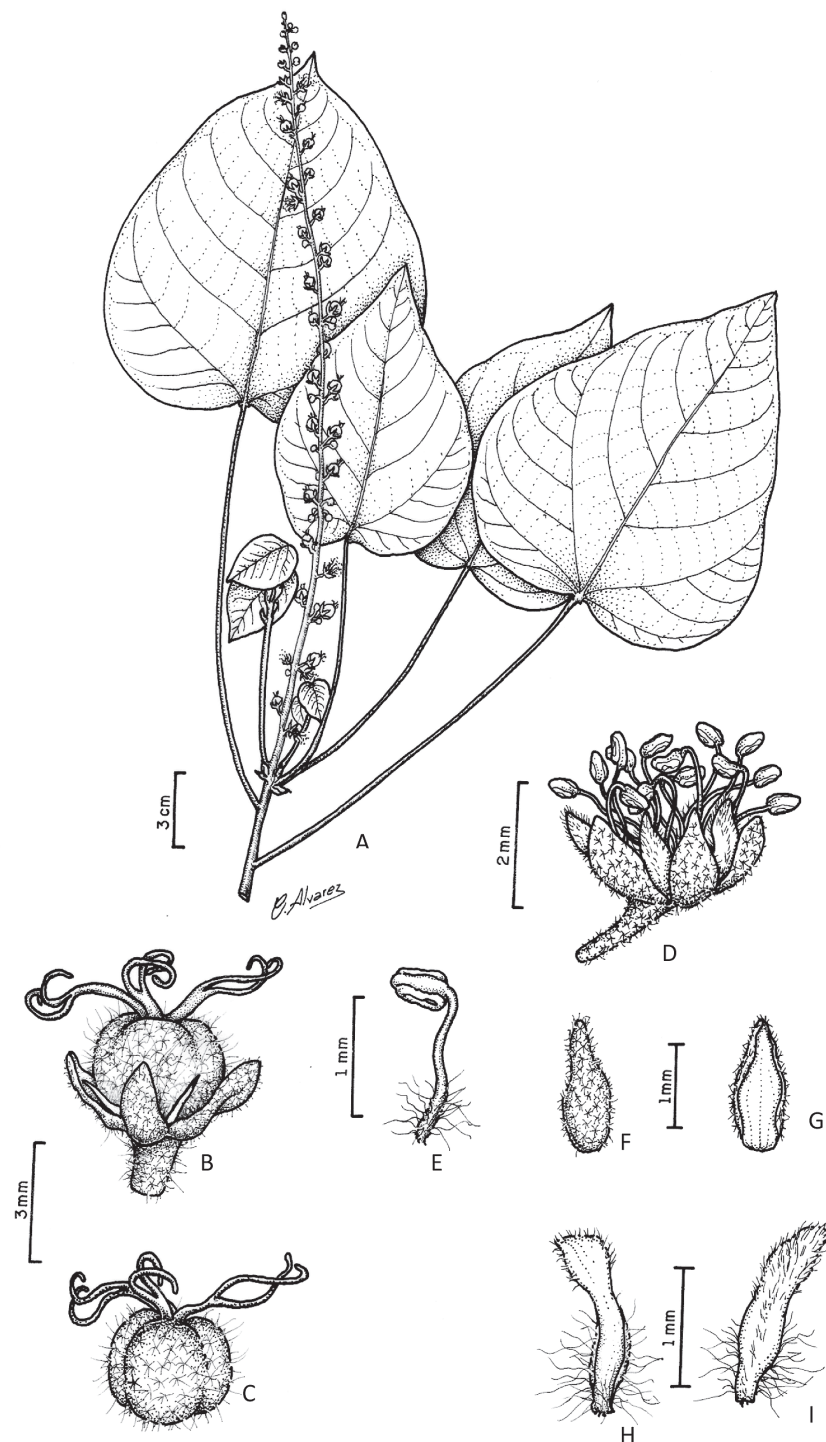

Figura 1- Croton urucurana Baill. A) Ramo; B) Flor pistilada; C) Gineceu; D) Flor estaminada; E) Estame; F)- Sépala da flor estaminada, face externa; G)- Sépala da flor estaminada, face interna; H)- Pétala da flor estaminada, face interna, detalhe da margem; I)- Pétala da flor estaminada, face externa. (A-I: Irwin, 1589).

Argentina, Paraguai e Uruguai. Segundo MOBOT (2008) ocorre também no Equador e no Peru.

Nomes populares. "Sangue-da-água", "sangra-d'àgua", "urucurana", "sangue-de-dragão", "sangre de drago", "capixingui", "tapixingui” etc. A denominação "sangre-dedrago" ("sangue-de-dragáo") é devido à presença de uma resina avermelhada, que lembra sangue, especialmente no caule da planta. O termo água, dos nomes populares, referese ao habitat preferencial da espécie (matas ciliares e de beira de rios). 
Material examinado. BRASIL. Amazonas, Três Casas, rio Madeira, Kublmann 316 (RB), s/d. (fl). Acre, Basiléia, basin of rio Purus, upper rio Acre, Daly et al. 9721 (MG), 22.III.1998 (fl, fr); Assis Brasil, basin of rio Purus, upper rio Acre, left bank, seringal Sáo Francisco, colônia Ipiranga, Daly et al. 9833 (MG), 27.III.1998 (estéril); rio Acre, Ule 9545 (MG), I.1912 (fr). Pará, Querência do Norte, Porto Natal, Córrego Juriti, 230.9'S 53⒊'W, altitude 230-240 m, Leite 009 (MG) 21.I.1986 (f). Mato Grosso, divisa territorial entre São Pedro da Cipa/ Juscimeira, fazenda do Sr. Aanael, Libério et al. 788 (MG), 10.XI.1998 (f); Maracaju, fazenda Sto. Antônio, mata ciliar, Sucre 10492 (RB), 29.XII.1973 (f). Brasília, elevação de 975 m, H. S. Irwin s/n. (MG), 18.V.1966 (f).

Croton urucurana Baill. é superficialmente semelhante a Croton draconoides Müll.Arg., mas pode ser distinguida pelas seguintes características: folhas com face abaxial tomentosa, alvacenta, ferrugínea nas nervuras, base acentuadamente cordada a auriculada e estípulas ovais, foliáceas. Além disso, em C. urucurana as flores estaminadas possuem pedicelo 3-3,5 mm compr., as pétalas internamente glabras, com tricomas simples, vilosos concentrados na margem, e as sépalas internamente glabras, ao passo que em C. draconoides tais flores apresentam pedicelo 8-9 $\mathrm{mm}$ compr., pétalas internamente com denso-indumento de tricomas simples, vilosos, e as sépalas internamente pubescentes.

De acordo com Webster (1993), C. urucurana pertence a Croton sect. Croton subsect. Cyclostigma (Griseb.) Müll.Arg.

Essa espécie foi detectada como primeira ocorrência nos Estados do Acre e Maranháo por Secco \& Cordeiro (2002)

2. Croton draconoides Müll. Arg., Linnaea 34: 90. 1865. Tipo. Brasil. In Brasilia inter Bahia et Vittoria, Sellow (B); Peru. In Peruvia orientali prope Tarapoto, Spruce 4582 (G!; K!, B), 1855-56; Peru, in Maynas Alto, Poeppig 1846 (B, W!) s/d. Figura 2.

Arbustos a árvores, 3-15 m alt. Ramos com denso indumento de tricomas estrelados, ferrugíneos; resina transparente, tornando-se avermelhada. Folhas $6-28 \mathrm{~cm} \mathrm{x}$ 4-15 cm, palmatinérvias, cordadas a oval-elípticas, cartáceas; face adaxial tomentosa, velutina quando jovem, indumento de tricomas estrelados, áspera quando adulta, face abaxial denso-velutina, inteiramente ferrugínea, tricomas estrelados, margem inteira a levemente ondulada, base cordada, com um par de glândulas achatadas, pateliformes, na face abaxial, ápice acuminado a caudado; pecíolo $1-20 \mathrm{~cm}$ compr., tomentoso, tricomas estrelados; estípulas 2, basais, 0,5-1 cm compr., filiformes. Inflorescência racemosa, axilar, às vezes terminal, $15-50 \mathrm{~cm}$ compr., raque pubescente, tricomas estrelados, flores pistiladas em menor quantidade, inseridas entre fascículos de flores estaminadas, ou apenas flores estaminadas na raque. Flores estaminadas com pedicelo $8-9 \mathrm{~mm}$ compr., com

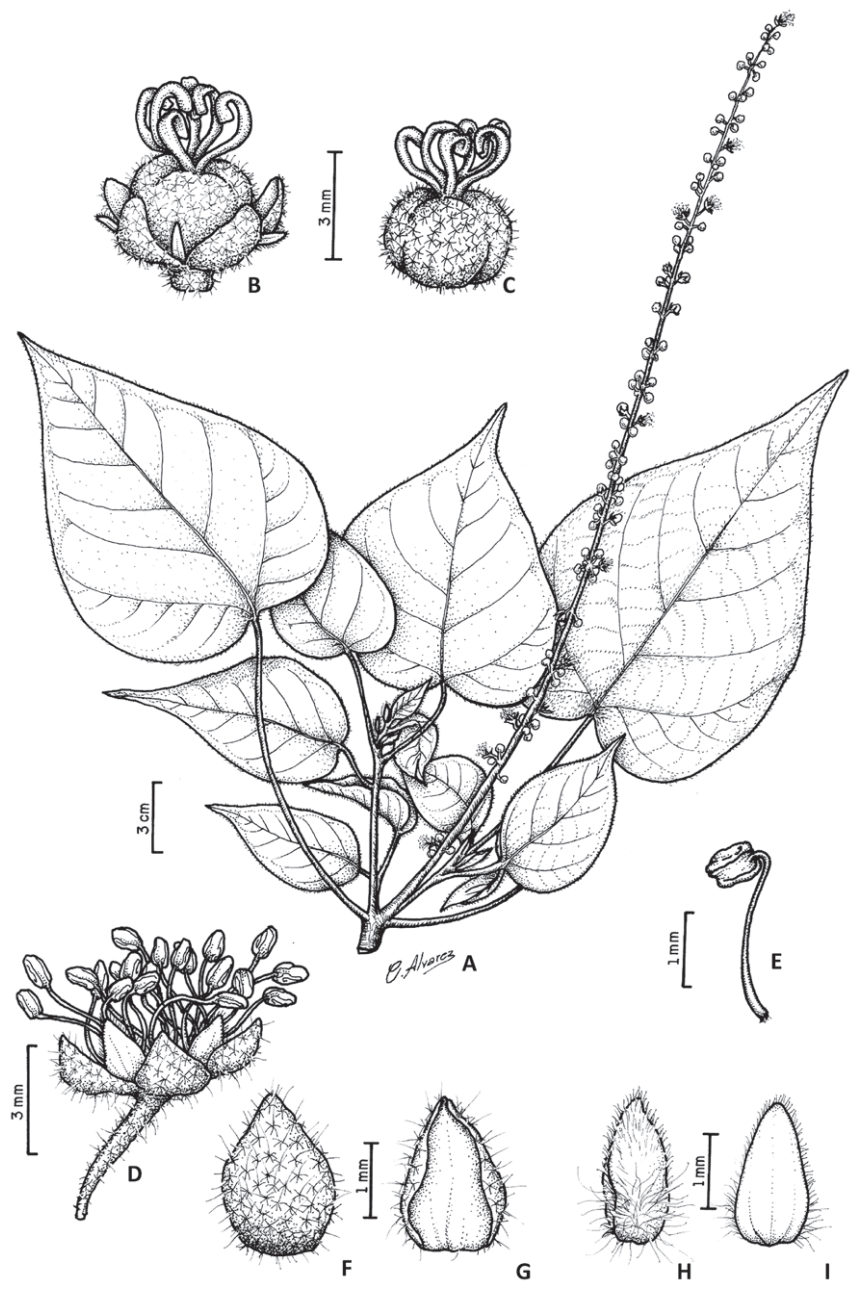

Figura 2- Croton draconoides Müll. Arg. A) Ramo; B) Flor pistilada; C) Gineceu; D) Flor estaminada; E) Estame; F) Sépala da flor estaminada, face externa; G) Sépala da flor estaminada, face interna; $H$ ) Pétala da flor estaminada, face interna; I) Pétala da flor estaminada, face externa. (A-I: Ducke, MG 453)

denso indumento de tricomas estrelados, cálice 5-lobado, lobos ovais, 2-2,5 mm compr., denso-pilosos, com tricomas estrelados externamente, pubescentes com tricomas simples, vilosos internamente e nas margens, pétalas 5, elíptico-ovais, 2-2,5 mm compr., denso indumento de tricomas simples, vilosos internamente e nas margens, glabras externamente, estames 15-20, 3-3,5 mm compr., filetes glabros, assentados em receptáculo com denso indumento de tricomas simples, vilosos, disco pentalobado. Flores pistiladas com pedicelo 1-1,5 mm compr., piloso, tricomas estrelados, cálice 5-lobado, quase livre, lobos regulares, simétricos, não reduplicados, elíptico-ovais, 2-2,5 $\mathrm{mm}$ compr., tricomas estrelados externamente, tricomas simples, vilosos na parte apical, internamente, pétalas 5 , extremamente reduzidas, obsoletas, como um filete carnoso de $0,5 \mathrm{~mm}$ compr., ovário $4-4,5 \mathrm{~mm}$ diâm., subgloboso, piloso, com denso indumento de tricomas 
estrelados a estrelado-dendríticos, de braços curtos, estiletes 3 , ramos profundamente bífidos, unidos apenas na base. Frutos ca. $7 \mathrm{~mm}$ diâm., subglobosos, rugosos, pubescentes, tricomas estrelados, cálice persistente na maturação. Sementes não vistas.

Distribuição. Pará, Maranhão, Rondônia, Guiana Francesa (coleção Oldeman 2002, IAN).

Nomes populares. "Murucucutu”, "sangra-d'água" (Pará).

Material examinado. BRASIL. Amazonas, Barcelos, 0-3 Km $\mathrm{N}$ do Km 211 da estrada Perimetral Norte, encosta do Pico Rondon, Amaral et al. 1455 (INPA, MG), 03.II.1984 (f). Pará, Altamira, Inferno Verde, dique 2, Dias et al. 609 (MG), 27.XI.1986 (f); Paragominas, fazenada Vitória, Cordeiro 2068 (IAN), 10.IV.91 (f); Ourilândia do Norte, Cordeiro 3088 (IAN), 01.II.1999 (f); Marabá, Serra dos Carajás, N.A Rosa et al. 4531 (MG), 07.XI.1983 (f); Nova-Canaã dos Carajás, L.C.B. Lobato et al. 2625 (MG), 27.XII.2000-06.I.2001 (fr); Marabá, Serra dos Carajás, 5047'S 5064’W, altitude $250 \mathrm{~m}$, Sperling et al. 6060 (MG), 10.VI.1982 (f); estrada para Itacaiunas, O. C. Nascimento \& R.P. Bahia 1088 (MG), 31.I.1985 (fl); roadside on BR-163, Cuiabá-Santarém road, $\mathrm{km} 881$, J.H. Kirkbride Jr. \& E. Lleras 2786 (INPA, MG, NY), 14.II.1977 (fl, fr); Tucuruí, fazenda Krinet, Km 74, José Ribeiro 0070 (IAN), 17.XI.1982 (fl, fr). Maranhão, São Vicente Ferrer, Santa Rosa, Secco \& N. A. Rosa 899 (INPA, MG, SP), 29.IV.1998 (fl); Piry-mirim, beira do campo baixo, A. Ducke MG 453a (MG), 30.IX.1903 (f); $453 b$ (MG), 30.IX.1902 (f); margem da estrada de S. João, arredores de S. Bento, N.A. Rosa 2495 (INPA, MG, NY, RB), 04.VII.1978 (f); Imperatriz, fazenda Antonio Passarinho, Pires 1731 (IAN), 7.VIII.1649 (f); contagem em campos temporariamente alagados de Pinheiro, 4-13, N.A. Rosa \& O. Cardoso 2663 (INPA, MG, NY), 12.VII.1978 (fr); Anajatuba, margem da estrada Colombo, Ribeiro \& Pinheiro 1244 (IAN), 27.I.1976 (f). Rondônia, Costa Marques, Resex do Caltário, terreno do Sr. Cuiabano, entre os rios Guaporé, Caltário e Ouro Fino, Luiz Carlos et al. 1137 (MG), 6.XI.1996 (fr).

Croton draconoides é uma espécie muito semelhante a C. lechleri Müll. Arg., proposta posteriormente por Müller (1866). Autores como Croizat (1944) e Macbride (1951) acreditam que as duas coleçôes-tipo do Peru, citadas por Müller (1865) na descrição original de C. draconoides, sejam C. lechleri.

Quanto à coleção-tipo Sellow, citada para o Brasil (entre Bahia e Vitória) na descrição de $C$. draconoides, foi destruída durante o bombardeio em Berlim, na Segunda Guerra Mundial. Provavelmente, tal material seria de C. urucurana, espécie que mantém semelhança com $C$. draconoides e distribui-se abundantemente no centro-oeste, nordeste, sudeste e sul do Brasil, com raras ocorrências no norte (Amazonas e Acre).
Em razão de não ter analisado a coleção Sellow, Brian Smith (comunicação pessoal, 2006) considera mais apropriado manter $C$. draconoides e $C$. lechleri como espécies válidas, sugerindo Sellow s/n. como lectótipo de $C$. draconoides.

Após analisar os síntipos do Peru, citados na descrição original de C. draconoides (coleçôes Poeppig 1846-W, e Spruce 4582-K), e comparando-os com os demais materiais examinados no presente trabalho, constatou-se as semelhanças entre $C$. draconoides e $C$. lechleri. Mas entende-se que este assunto ainda não está bem esclarecido, sendo que provavelmente o nome $C$. draconoides, de acordo com o Código Internacional de Nomenclatura Botânica, deverá ter prioridade sobre C. lechleri, considerando-se que tal espécie foi descrita primeiro (em 1865)

A distinção entre Croton urucurana e $C$. draconoides pode ser feita principalmente pelo indumento foliar (face abaxial velutina e ferrugínea) típico de $C$. draconoides, além das demais características morfológicas apontadas na chave e nos comentários de C. urucurana.

3. Croton trombetensis R. Secco; P.E. Berry \& N.A. Rosa, Novon 11: 119-123. 2001. Tipo. Brasil. Pará, município de Porto Trombetas, R. P. Salomão 880 \& N.A. Rosa (holótipo, MG!; isótipos, IAN!, INPA!, NY!), 01.I.1998 (fl, fr). Figura 3.

Árvores, $12-15 \mathrm{~m}$ alt. x 55-60 cm diâm. (DAP). Ramos com indumento tomentoso de tricomas estrelados. Folhas $14-30 \mathrm{~cm} \times 10-16 \mathrm{~cm}$, palmatinérveas, cordadas, cartáceas a subcoriáceas; com denso indumento de tricomas estrelados em ambas as faces, a face adaxial velutina ao toque, a abaxial áspera, com glândulas estipitadas, margem denteada, base cordada, com 2-3 glândulas, ápice caudado; pecíolo 10-24 $\mathrm{cm}$ compr., com denso indumento de tricomas estrelados. Inflorescência em tirso-racemiforme, terminal, 40-60 cm compr., a raque com denso indumento de tricomas estrelados, as flores agrupadas em fascículos, as estaminadas em maior número, misturadas com as pistiladas. Flores estaminadas com pedicelo $0,8-1,0 \mathrm{~cm}$ compr., pubescente, tricomas estrelados, cálice 5-lobado, lobos elíptico-ovais, 2,5-3 mm compr., com tricomas estrelados externamente, glabros internamente, tricomas simples, vilosos nas margens, pétalas 5, estreitolanceoladas, $3 \mathrm{~mm}$ compr., glabras externamente, com tricomas simples, vilosos internamente, estames 16, 5-6 mm compr., filetes glabros, inseridos em receptáculo com tricomas simples, vilosos. Flores pistiladas com pedicelo espesso 3-4 $\mathrm{mm}$ compr., pubescente, tricomas estrelados, cálice 5-lobado, lobos ovais, 1,5-2 mm compr., com tricomas estrelados externamente, esparso indumento de tricomas estrelados e simples internamente, pétalas 5-6, estreitas, 1,5-2 mm compr., bem separadas entre si, glabras externamente, com tricomas vilosos internamente, ovário $4 \mathrm{~mm}$ diâm., subgloboso, piloso, tricomas estrelados, disco segmentado na base, estiletes 3, 


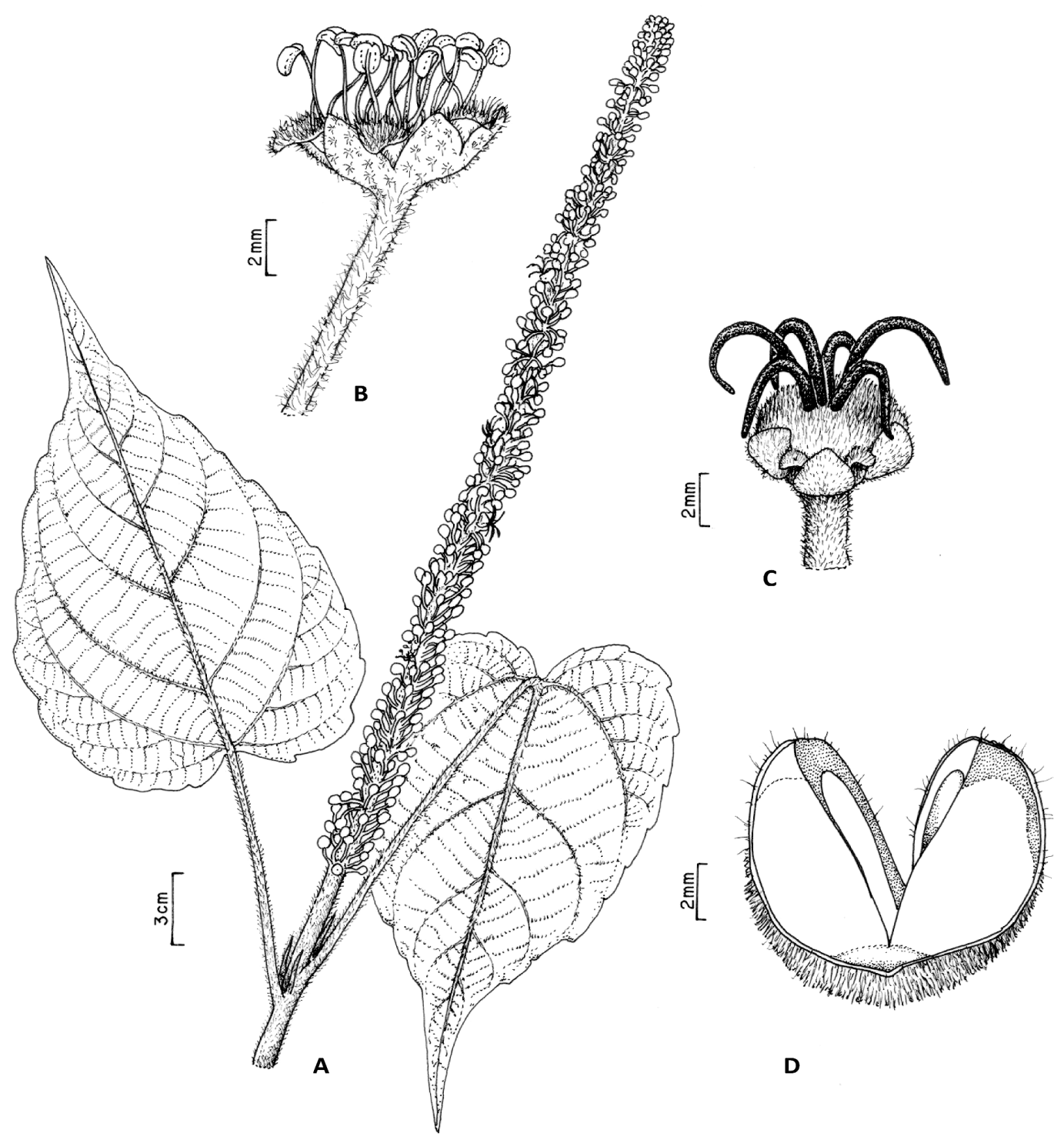

Figura 3- Croton trombetensis R. Secco, P.E. Berry \& N.A. Rosa. A) Ramo; B) Flor estaminada; C) Flor pistilada; D) Detalhe de um mericarpo após deiscência do fruto (A-D: Salomão \& Rosa, 880).

os ramos bífidos, 7-8 mm compr., pubescentes, tricomas estrelados. Frutos $1 \mathrm{~cm}$ diâm., subglobosos, indumento denso de tricomas estrelados; sementes 6-7 mm diâm., pintalgadas, carunculadas.

Distribuiçáo. Brasil: Pará.

Nome popular. "pau-de-índio" (PA).

Material examinado. Pará, município de Oriximiná, rio Trombetas, Flona Saracá-Taqüera/IBAMA, Porto Trombetas, Salomão et al. 952 (MG), 16.I.2003 (fr).
Croton trombetensis caracteriza-se por ser uma árvore de 12-15 m de altura e 55-60 cm de diâmetro (DAP). As folhas têm a base auriculada, com um denso indumento de tricomas estrelados em ambas as faces, estípulas longas, aciculadas (1-1,3 cm de comprimento), várias glândulas estipitadas na face abaxial e 2-3 glândulas na base do limbo. Além disso, possui inflorescências longas em tirso-racemiforme, terminais, robustas ( $40 \mathrm{a} 46 \mathrm{~cm}$ de comprimento), as flores estaminadas em fascículos, estando as pistiladas misturadas com várias estaminadas. 
As afinidades deste táxon ainda são obscuras, pois, segundo Secco et al. (2001), entre as espécies conhecidas na Amazônia brasileira não foi detectada nenhuma com semelhanças morfológicas com $C$. trombetensis.

Entretanto, por apresentar as folhas palmatinérveas, com margem denteada, com denso indumento de tricomas estrelados na face abaxial, glândulas na base do limbo, inflorescência com fascículos basais bissexuados, terminal, estames 16, pétalas nas flores pistiladas e estiletes bífidos, $C$. trombetensis enquadra-se melhor em Croton sect. Cyclostigma Griseb. subsect. Cyclostigma (Griseb.) Müll. Arg., segundo um sistema revisado proposto por Webster (1993).

4. Croton sampatik Müll. Arg., Linnaea 34: 94. 1865. Tipo. Peru. Ruiz 597 (holótipo, G!; isótipo, B).Figura 4.

Árvores, $12-20 \mathrm{~m}$ de alt. Ramos com tricomas lepidotoestrelados. Folhas $9 \cdot 5-19 \times 5-9 \cdot 5 \mathrm{~cm}$, trinervadas na base, ovais a oval-lanceoladas, cartáceas a membranáceas; face adaxial com nervuras levemente proeminentes a planas, esparsamente pubescente, os tricomas lepidoto-estrelados concentrados nas nervuras, face abaxial com nervuras proeminentes, indumento de tricomas lepidoto-estrelados; margem espaçadamente denteada, base cordada com um par de glândulas salientes, verrucosas, ápice acuminado; pecíolo 2,5-5,5 cm compr., cilíndrico a levemente canaliculado, pubescente, indumento de tricomas lepidoto-estrelados. Inflorescência estaminada racemosa, terminal e axilar, $12-20 \mathrm{~cm}$ compr., raque com denso indumento de tricomas lepidoto-estrelados, as flores dispostas em fascículos. Flores estaminadas com pedicelo 0,5-0,8 cm compr., pubescente, tricomas estrelados, cálice 5-lobado, os lobos sagitados, $2 \mathrm{~mm}$ compr., pubescentes externamente, tricomas estrelados, pétalas 5, elípticas, livres, 2-2,5 mm compr., indumento de tricomas simples, vilosos internamente, concentrados nas margens e parte apical, glabras

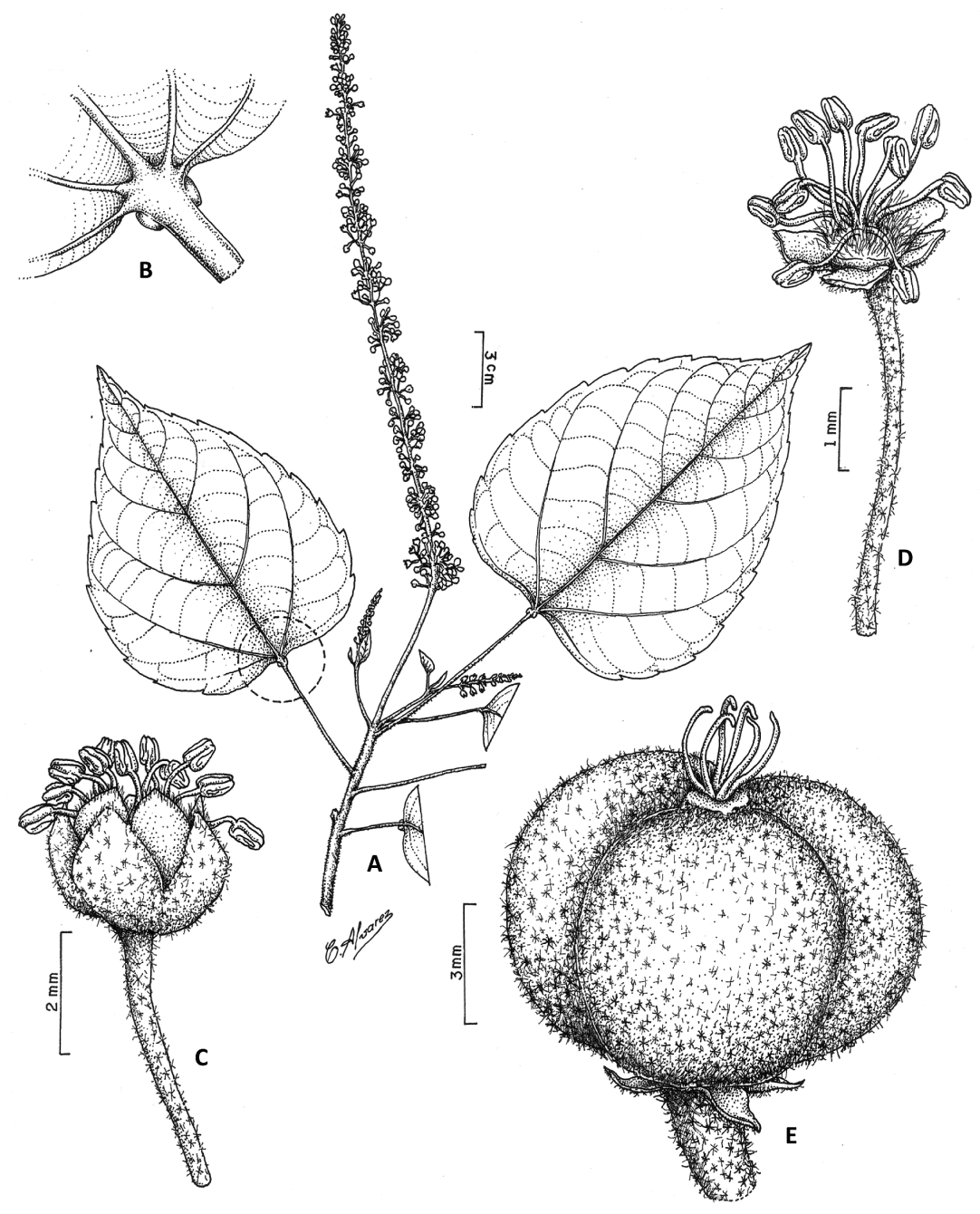

Figura 4- Croton sampatik Müll. Arg. A) Ramo com inflorescência; B) Detalhe da base da folha com 1 par de glândulas, em vista abaxial; C) Flor estaminada; D) Flor estaminada, sem as pétalas, com estames em tufo de tricomas; E) Fruto. (A-E: Vicentini, 735). 
externamente, estames 11-12, 2-2,2 mm compr., livres, filetes glabros, anteras ovais, assentados em um tufo de tricomas simples, vilosos, disco obsoleto. Inflorescência bissexuada (em estágio muito jovem) em racemo espiciforme, terminal, raque tomentosa com tricomas estrelados, as flores pistiladas na base, as estaminadas no restante da raque. Flores pistiladas em estágio muito jovem; flores pistiladas (ainda jovens) com pedicelo $1 \mathrm{~mm}$ compr., tomentoso, tricomas estrelados; cálice 5-lobado, lobos lanceolados, ca. $2 \mathrm{~mm}$ compr., indumento de tricomas estrelados externamente, ovário 1,5-2,0 mm diâm., subgloboso, tomentoso, indumento de tricomas estrelados. Frutos $1 \mathrm{~cm}$ diâm., com deiscência loculicida, indumento de tricomas estrelados; sementes $6 \mathrm{~mm}$ compr., lisas, pintalgadas, ecarunculadas.

Distribuiçáo. Brasil: Amazonas e Pará.

Material examinado. BRASIL. Amazonas, estrada ManausItacoatiara, Km 26, Reserva Ducke, Vicentini, A. \& Pereira, E. da C. 735 (IAN, INPA, K, MG, MO, NY, RB, SP, UB), 12.X.1994 (f); Ibidem, idem 1164 (INPA, K, MG, MO, NY, RB, SP), 12.XII.1995 (fr); Presidente Figueiredo, Balbina, 0102'S 5960'W, C. A. Cid et al. 6658 (INPA), 08.III.1986 (fr); Manaus, rodovia BR 174, km 64, fazenda P. Velho, $C$. Dick 104 (INPA), 11.IV.1992 (f). Pará, Oriximiná, 14 km Cachoeira Porteira, estrada para a Perimetral Norte, Cid Ferreira 9701 (INPA, NY, MG, RB), 27.XI.1987 (f).

Croton sampatik é facilmente identificável pelas folhas ovais, com base trinervada, e face abaxial pubescente com tricomas concentrados nas nervuras; as flores estaminadas são pediceladas, dispostas em fascículos e o androceu é composto por 11 a 12 estames, glabros, assentados em um tufo de tricomas simples, vilosos, que cobre o receptáculo floral; as sementes são lisas, pintalgadas e ecarunculadas.

Esta espécie ainda é mal coletada na Amazônia, sendo por isso ainda pouco conhecida na regiáo. As flores pistiladas e a inflorescência bissexuada aqui analisadas estavam em estágio jovem, o que demonstra que novas coleçóes devam ser estudadas para complementar a presente descrição da espécie.

5. Croton palanostigma Klotzsch, in Hook. London Journ. Bot. 2: 48. 1843. Tipo. Brasil. In vicinibus Barra, prov. Rio Negro, Spruce s/n. (holótipo, B; isótipos, BM!, G!, W!), XIIIII.1850-51 (fl, fr). Figura 5.

Croton benthamianus Müll. Arg., Euphorbiaceae. Flora brasiliensis 11(2): 105. 1873. Tipo. British Guiana, Schomburgk 1008 (holótipo, G; foto do holótipo, F!).

Arvoretas a árvores, 3-12 m alt. Ramos pulverulentos, tricomas estrelado-lepidotos. Folhas de tamanhos variados, ca. 8-27 cm x 7,5-16,5 cm, trinervadas na base, cordadas, às vezes cordado-lobadas, subcoriáceas a cartáceas, pubescentes em ambas as faces, tricomas estrelados a estrelado-lepidotos, velutinas a ásperas ao tato, margem inteira ou discretamente

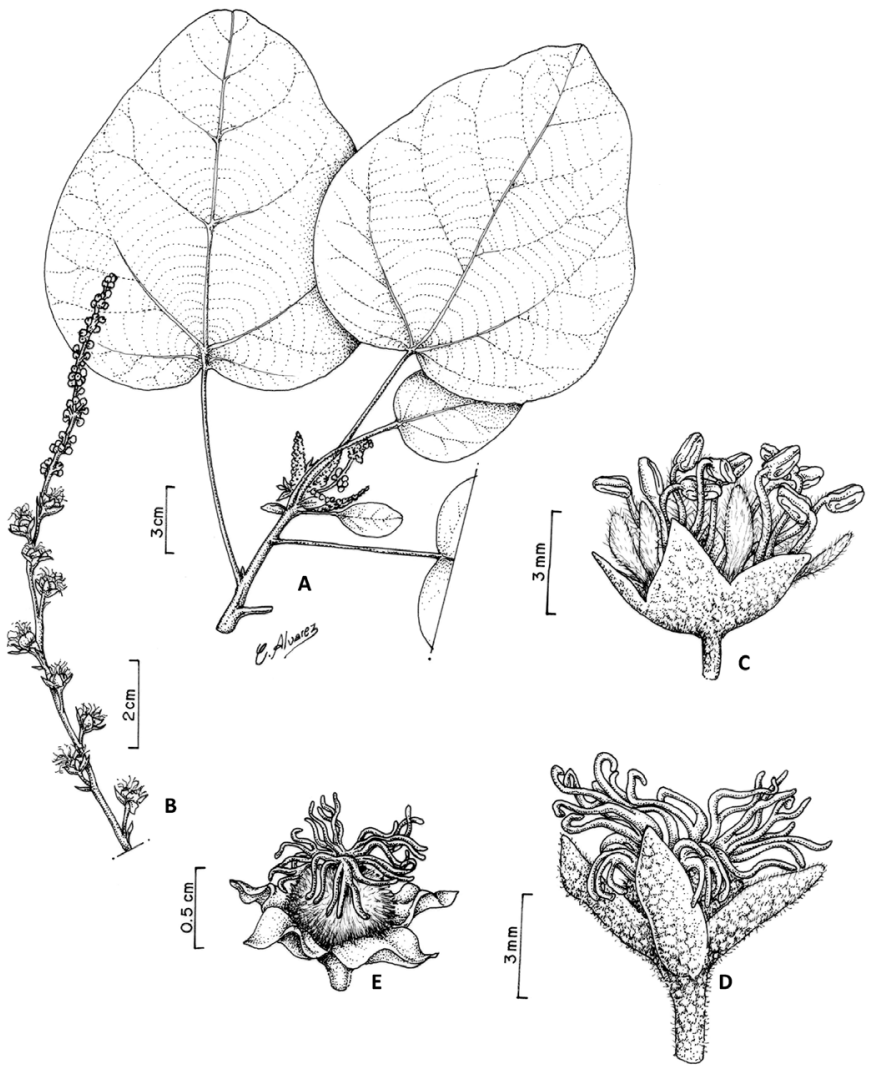

Figura 5- Croton palanostigma Klotzsch. A) Ramo; B) Inflorescência com flores pistiladas na base e estaminadas no ápice; C) Flor estaminada; D) Flor pistilada; E) Flor pistilada com sépalas abertas, mostrando o gineceu. (A: Cordeiro, 192; B-E: Murça Pires, 16943).

ondulada, às vezes com glândulas capitadas na face abaxial, base cordada a aguda, raro levemente cuneada, com um par de glândulas, ápice agudo a acuminado; pecíolo 2-12 cm compr., piloso, tricomas estrelado-lepidotos. Inflorescência tirsoracemiforme, terminal e axilar, $12-40 \mathrm{~cm}$ compr., bissexuada, raque pubescente, tricomas estrelado-lepidotos, com flores pistiladas 1-3, misturadas com um grupo de estaminadas, formando fascículo; ou inflorescência racemosa, unissexuada, com apenas flores pistiladas. Flores estaminadas com pedicelo 1,5 mm compr., piloso, tricomas estrelado-lepidotos, cálice 5-lobado, lobos sagitados, 3,5-4 mm compr., com tricomas estrelado-lepidotos externamente, glabros internamente, pétalas 5 , lanceolado-espatuladas, $5 \mathrm{~mm}$ compr., tricomas simples, vilosos nas margens externamente, e na parte apical, internamente, estames 10-11, sendo 1 central, 4,5$5 \mathrm{~mm}$ compr., filetes com tricomas simples, vilosos. Flores pistiladas com pedicelo $4 \mathrm{~mm}$ compr., piloso, tricomas estrelado-lepidotos, cálice 5-lobado, lobos sagitados, regulares, simétricos, 5-6 mm compr., piloso externamente, tricomas estrelado-lepidotos, com tricomas simples, vilosos apenas na margem, internamente, pétalas ausentes ou obsoletas, ovário 
3,5-4 mm diâm., subgloboso, piloso, tricomas estreladodendrítcos e estrelado-porrecto, disco 5-lobado, estiletes 3, multífidos, pubescentes, tricomas estrelados. Frutos 0,8-1 cm diâm., subglobosos, pilosos, tricomas estrelado-porrectos, estiletes persistentes, velutinos, aracneiformes. Sementes não vistas.

Distribuiçáo. Brasil: Roraima, Amazonas, Acre, Pará e Rondônia.

Nomes populares. "Balsa-rana", "balsarana", "mameleiro" (Amazonas).

Material examinado. BRASIL. Roraima, serra dos Surucucus, Prance et al. 13515 (MG), 6.II.1971 (fl); rio Uraricoera, serra Cura-ci-ha, $600 \mathrm{~m}$ alt., Murça Pires et al. 16943 (MG, NY, RB), 11.III.1979 (f); estrada ManausCaracaraí, BR 174, I. Cordeiro et al. 34 (INPA, MG, N), 15.VI.1985 (fl, fr). Amazonas, Tefé, lago Tefé, 3²0'S 64050'W, Plowman et al. 12514 (INPA, MG, NY, RB), 1114. XII.1982 (fr); road Humaitá to Lábrea, savanna, Prance \& Ramos 3409 (INPA, MG, NY), 27.XI.1966 (fl); Manaus, estrada da Raiz, capoeira, Ducke 383 (IAN), 16.XII.1942 (fl, fr); São Gabriel da Cachoeira, serras radioativas, Pires \& Marinho 15806 (IAN), 13.III.1975 (fr); Alvarás, rio Solimóes, mata de terra firme, 313'S 64050'W, I. Amaral et al. 663 (INPA, RB), 29.XI.1982 (fr); Manaus, margem do igarapé Candinha, capoeira T. firme, Chagas s/n (MG 21517, RB), s/d. (f); Solimóes, Tonantins, mata de terra firme, Kublmann 1245 (MG), 24.I.1940 (fl, fr); Tonantins, capoeirāo de terra firme, Ducke 1564 (IAN, MG), 24.II.1944 (f); Barcelos, talude da Serra do Araçá, $300 \mathrm{~m}$ de Alt., 0050’N 6321'W, Cordeiro 225 (INPA), 20.VII.1985 (fl); Barcelos, margem do rio Javari, rio Araçá, $15 \mathrm{Km}$ da serra do Aracá, mata alagável, $00^{\circ} 42^{\prime} \mathrm{N}$ 63⒉'W, I. Cordeiro 192 (INPA, MG); Manaus, margem da Cachoeira baixa do Tarumã, capoeira fechada, Dionísio s/n (MG 21894), 19.XII.1955 (f); São Gabriel da Cachoeira, morro dos Seis Lagos, scrub and low Forest on steep, hilly, rock terrain, Daly et al. 5418 (INPA, MG, NY), 15.X.1987 (f); baía de Buiaçu, lower rio Negro, Prance et al. 11486 (INPA, MG, NY), 27.I.1971 (fl); rio Mapari, end of road, ca. $30 \mathrm{~km}$ E of Borba, Todzia et al. 2241 (INPA, MG, NY), 24.VI.1983 (fl, fr); Manaus, BR 17, km 21, Luis \& Francisco INPA 3224 (INPA), 30.XII.1955 (f); terra firme, Cavalcante 728 (INPA, MG), 03.III.1959 (fr); cachoeira baixa do Tarumã, beside river, Prance et al. 3857 (INPA, NY), 02.I.1967 (f); enseada Grande, Tarumã, W. Rodrigues \& L. Coelho 2087 (INPA), 17.I.1961 (f); Manaus, BR 17, km 8, Rodrigues \& Chagas 1548 (INPA), 31.III.1960 (f). Acre, serra da Moa, rio Moa, Forest on Hill slopes, Prance et al. 12453 (INPA, MG, NY), 25.IV.1971 (fl); prefeitura de Cruzeiro do Sul, $2 \mathrm{~km}$ do centro da cidade de CZS ao aeroporto, Pollito \& Dantas 2945 (MG, UFAC), 01.XII.2002 (f); Rio Javari, aeroporto de Palmeira, RADAM, capoeira de terra firme, Mota
305 (MG), 5.IV.1976 (fr). Pará, roadsisde on BR 163, CuiabáSantarém, Km 886, Kirkbride \& LLeras 2775 (INPA, MG), 17.II.1977 (fl, fr); rio Trombetas, planalto Saracá, mata de terra firme, N. T. Silva \& Santos 4650 (MG), 27.V.1978 (fr); Oriximiná, rio Trombetas, C. A. Cid \& J. Ramos 1037 (INPA, RB), 18.VI.1980 (f); Flona Saraca-Taqüera/IBAMA, Porto Trombetas, Oriximiná, Salomão et al. 960 (MG), 16.I.2003 (f); campos do Ariramba, Oriximiná, Martinelli 6928 (MG, RB), 8.VI.1980 (f); Capitão Poço, Centro de treinamento do IDESP, E. Oliveira 6402 (MG), 19.II.1976 (f); beira da estrada do Piri, terra firme, E. Oliveira $6167(\mathrm{MG}), 3 . \mathrm{IV} .1974$ (fr); Pará, município de Terra Alta, próximo de Castanhal, beira de mata secundária, $R$. Secco et al. 928 (IAN, MG), 23 mar. 2007 (fl, fr); ilha do Mosqueiro, L. 19, Q. 18, Pau Amarelo, E. Oliveira 5933 (IAN), 18.X.1971 (est); Óbidos, rio Cuminá-miri, Cavalcante 188 (MG), 9.VI.1957 (f); Serra do Cachimbo, BR 163, Cuiabá-Santarém highway, cachoeira de Curuá, Prance et al. 24864 (MG, NY), 5.XI.1977 (fl). Rondônia, margin of Mutumparaná airstrip, savanna forest, Prance et al. 8855 (MG, NY), 25.XI.1968 (f); Machadinho d'Oeste, distrito de Tabajara, campina semiaberta, Lobato et al. 2061 (MG), 8.XI.1997 (f); Vilhena, mata de t. firme, $M$. Silva \& Pinheiro 4177 (INPA, MG), 6.I.1979 (fl, fr); estrada do rio Pimenta Bueno, localidade Guaporé, $12^{\circ} 45^{\prime} \mathrm{S} 60^{\circ} 10^{\prime} \mathrm{W}$, Vieira et al. 989 (INPA, NY, RB).

Croton palanostigma caracteriza-se pelas folhas com ápice agudo, mais raro curto-acuminado, as flores estaminadas e pistiladas com tricomas estrelado-lepidotos e pelo androceu formado por 10 a 11 estames. Pode apresentar algumas folhas lobadas no mesmo ramo, mas o coautor estudou populações naturais no município de Terra Alta (Pará) e não encontrou nenhum indivíduo com tal característica.

6. Croton pullei Lanj., Euphorb. of Surinam 18, pl. 3. 1931. Tipo. Surinamae. Upper Surinam river, Stahel 76 (holótipo, U!). Figura 6.

Lianas lenhosas ou arvoretas com ramos escandentes, ca. 3-5 m alt. Ramos pubescentes, tricomas estrelado-lepidotos, glabrescentes. Folhas 7,5-24,5 cm X 3,5-12,5 cm, peninérveas, cordadas, às vezes elípticas a elíptico-oblongas, cartáceas a subcoriáceas; ambas as faces pubescentes, especialmente a abaxial, glabrescentes, os tricomas estrelado-lepidotos geralmente esparsos entre si, nervuras perceptíveis, a olho nu, em ambas as faces, margem inteira, base cordada, cordado-auriculada, arredondada, às vezes reta, com um par de glândulas arredondadas, às vezes ocultas pelos tricomas, ápice acuminado, às vezes caudado; pecíolo $2-9 \mathrm{~cm}$ compr., pubescente, tricomas estrelado-lepidotos. Inflorescência racemosa, 20-45 cm compr., terminal, (às vezes geminada, acompanhada de outra menor, com 3,5-7 cm compr., lateral, na maioria das vezes com número maior de flores pistiladas), raque pubescente, tricomas estrelados, as flores 


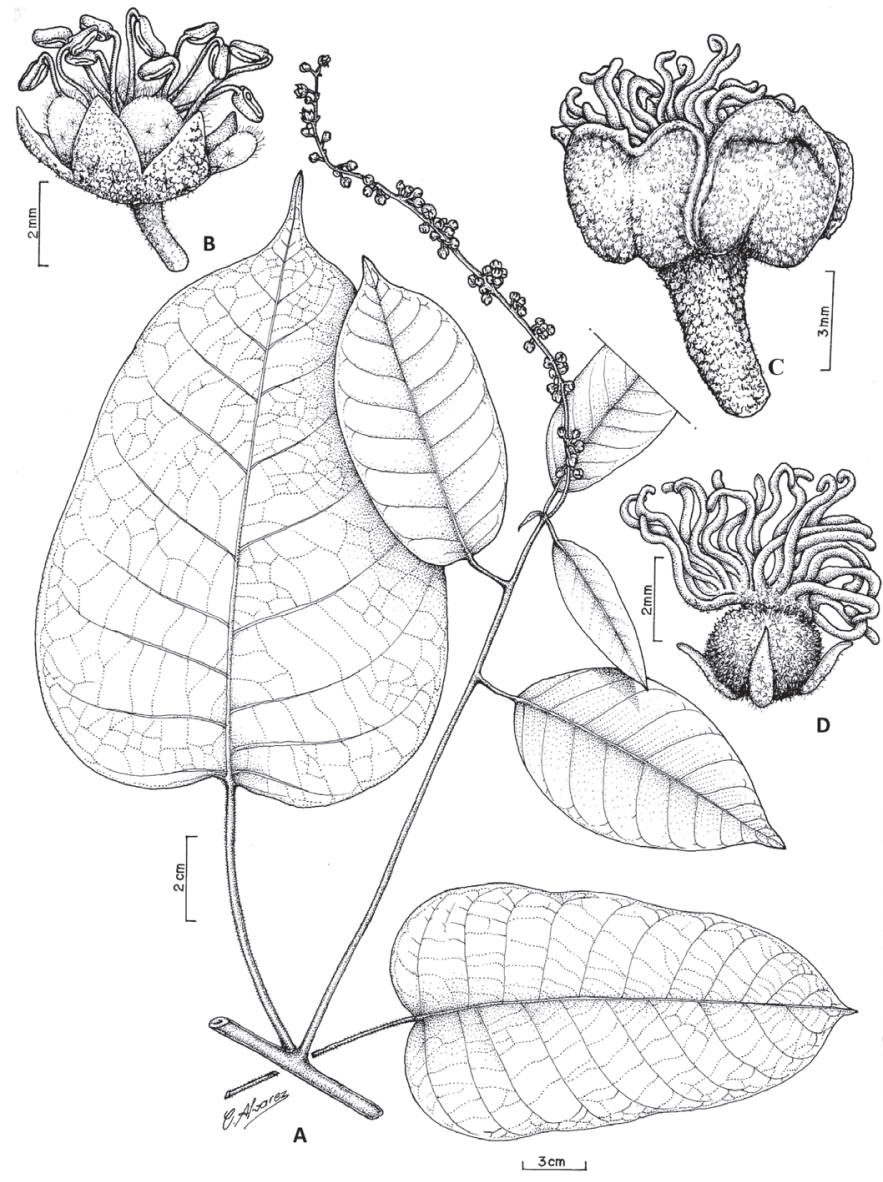

Figura 6- Croton pullei Lanj. A) Ramo; B) Flor estaminada; C) Flor pistilada com os lobos do cálice assimétricos, reduplicados; D) Flor pistilada sem 0 cálice, mostrando o gineceu e as pétalas. (A-D: Cavalcante, 2461).

pistiladas isoladas na base ou misturadas com as estaminadas, estas em fascículos no restante da raque. Flores estaminadas com pedicelo 3-3,5 mm compr., piloso, tricomas estreladolepidotos, cálice 5-lobado, lobos ovais a sagitados, 3-3,5 mm compr., pilosos externamente, tricomas estrelado-lepidotos, margem ciliada, glabros internamente, pétalas 5, elíptico-ovais, 3,5 mm compr., tricomas estrelados esparsos externamente ou glabras, margem ciliada, tricomas simples, vilosos, internamente, estames 11, 4-4,5 mm compr., filetes levemente conados na base, com tricomas simples, vilosos, disco basal lobado. Flores pistiladas com pedicelo 5,5-6 mm compr., grosso, subulado, piloso, tricomas estrelado-lepidotos, cálice 5-lobado, reduplicado (lobos com ondulaçóes), lobos carnosos, irregulares, assimétricos, 5,5 mm compr., pilosos externa e internamente, tricomas estrelado-lepidotos, ferrugíneos e prateados, pétalas 5, reduzidas, lanceoladas, 1-1,2 mm compr., levemente pubescentes, tricomas estrelados; ovário 2,5-3 mm diâm., subgloboso, piloso, tricomas estrelados, ferrugíneos, estiletes 3, multífidos, aracneiformes, denso-pilosos, tricomas estrelados. Frutos não vistos.

Distribuiçáo. No Brasil esta espécie ocorre apenas nos estados do Pará e Maranhão

Material examinado. BRASIL. Pará, Oriximiná, margem esquerda da estrada de Cachoeira Porteira, terra firme, $C$. A. Cid \& Ramos 1037 (INPA, MG), 18.I.1980 (fl); Ibidem, margem do rio Cachorro, próximo do barracáo do Ponto da Serra, 12 km NW de Cachoeira Porteira, 22.VI.1980, fl, Martinelli 7058 (RB, NY, INPA); Capitão Poço, Centro de Treinamento do IDESP, capoeira de terra firme, E. Oliveira 6261 (MG), 25.II.1975 (f); rio Parú do Oeste, missão Tiriyó, arredores da Missão, margem da mata e capoeira, Cavalcante 2565 (MG), 01.V.1970 (f); rio Trombetas, Oriximiná, rio Caxipacoro, Davidson \& Martinelli 10650 (INPA, MG, NY, RB), 31.VI.1980 (fr); Peixe-boi, fazenda Monte Verde, mata de terra firme, Secco \& Rosa 790 (MG), 13.V.1992 (fl); BR 163, Cuiabá-Santarém highway, Km 1305, vicinity of forest of terra firme, Prance et al. 25653 (MG, NY), 22.XI.1977 (A); rio Cachorro, afluente do rio Trombetas, cachoeira de São Pedro, Coelho et al. 227 (INPA), 21.XI.1985 (fl). Maranháo, fazenda São Francisco, estrada Alto Alegre-Lago Verde, Km 9, município Lago Verde, mata primária, Anderson et al. 2064 (MG), 21.III 1985 (fr).

Croton pullei destaca-se entre as espécies aqui estudadas principalmente por ser uma liana e apresentar o cálice da flor pistilada com os lobos irregulares, assimétricos e reduplicados. Um espécime de $C$. pullei, procedente do município de Peixeboi, no Pará, e cultivado no campus de pesquisa do Museu Goeldi, em Belém, revelou-se com hábito misto, sendo uma arvoreta de ramos decumbentes, tendendo a ser um cipó.

7. Croton matourensis Aubl., Hist. Pl. Guiane 2: 879, t. 338. 1775. Tipo. French Guiane. Aublet s/n (holótipo, P; isótipo, BM!). Figura 7.

Croton matourensis var. benthamianus Müll. Arg., Linnaea 34:95.1865. Tipo. Brasil. In vicinibus Barra, prov. Rio Negro, Spruce (holótipo, G!; isótipo, W!), mart. 1850-51.

Croton matourensis var. poeppigianus Müll. Arg., Linnaea 34: 95. 1865. Tipo. Peru, Maynas, Poeppig (holótipo, G!; isótipos, B, W!; foto do tipo, G!), dez. 1830 (fl).

Croton caryophyllus Benth., Hooker's J. Bot. Kew Gard. Misc. 6: 374. 1854. Tipo. In vicinibus Barra, Prov. Rio Negro, R. Spruce (holótipo, K!; isótipos, BM!, G!, W!; foto do holótipo, A!), dec.-mart. 1850-51 (fl). Syn. Nov.

Croton lanjouwensis Jabl., Mem. New York Bot. Garden 12: 158. 1965. Tipo. Brasil. In Brasilia septentrionalis prov. Rio Negro prope Barra, R. Spruce Crot. n. 2 (Holótipo, BM; Isótipo, NY!; fotos do isótipo, A!, IAN!, NY!). 


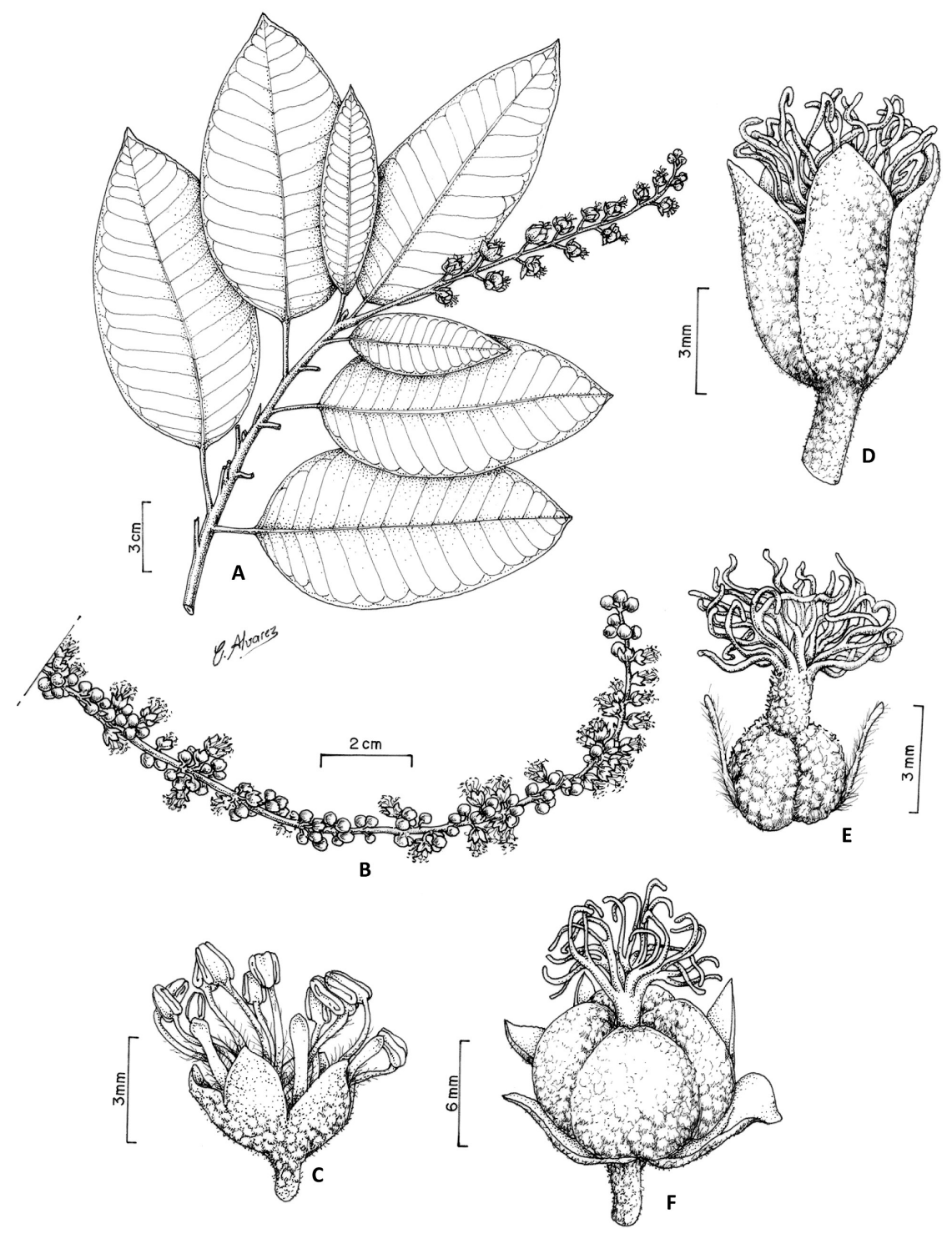

Figura 7- Croton matourensis Aubl. A) Ramo com inflorescência bissexuada; B) Detalhe da inflorescência com flores estaminadas em fascículos; C) Flor estaminada; D) Flor pistilada; E) Gineceu; F) Fruto. (A: Secco, 762; B-D: Rocha, 35).

Croton pakaraimae Jabl., Mem. New York Bot. Gard. 12: 159. 1965. Tipo. British Guiana, Pakaraima Mountains, Kopinang savanna, Maguire et al. 46023 A (holótipo, NY!; isótipo, MO!).

Arbustos a árvores, 2-15 m alt. Ramos denso-pilosos a glabrescentes, tricomas lepidotos, ferrugíneos, escamosos ou velutinos ao tato. Folhas de tamanhos variados, ca. $6-22 \mathrm{~cm} \mathrm{X}$ 3-9,5 cm, peninérveas, elípticas a elíptico-oblongas, discolores, cartáceas; face adaxial glabra ou com tricomas lepidotos na nervura central, face abaxial com denso indumento de tricomas lepidotos, e glândulas capitadas, dando-lhe um aspecto metálico-ferrugíneo, dourado, muito típico, margem inteira, base obtusa, com um par de glândulas capitadas, achatadas, às vezes obsoletas, ápice acuminado, raro agudo; pecíolo $1-4,5 \mathrm{~cm}$ compr., denso-piloso, tricomas estreladodendrítcos, velutino ou áspero ao tato, estípulas basais 2 , lanceoladas. Inflorescência em tirso-racemiforme ou racemosa, terminal, às vezes axilar, 8-22 cm compr., raque pubescente, tricomas lepidotos, bissexuada, as flores pistiladas na base, as estaminadas no restante da raque, ou unissexuadas, com apenas flores estaminadas. Flores estaminadas com pedicelo 1 $\mathrm{mm}$ compr., piloso, tricomas lepidotos, cálice 5-lobado, lobos sagitados, 4,5-5 mm compr., denso-pilosos externamente, tricomas lepidotos, glabros internamente, pétalas 5, estreito- 
lanceoladas, 4-4,5 mm compr., com tricomas simples, vilosos, apenas na margem, especialmente na metade basal, estames (10-)11, 5-6(-8) mm compr, filetes com tricomas simples, vilosos. Flores pistiladas com pedicelo 4,5-5 mm compr., denso-piloso, tricomas lepidotos, cálice 5-lobado, 6-7(8) mm compr., fendido apenas no ápice, lobos reduzidos, 2-2,5 mm compr., ou quase livres, lobos lanceoloados, $6-8 \mathrm{~mm}$ compr., denso-pilosos externamente, tricomas lepidotos, pilosos internamente, tricomas simples, vilosos, pétalas reduzidas, lineares, 1-1,5 mm, ovário 3,5 mm diâm., trígono, densopiloso, tricomas lepidotos, estiletes 3, concrescidos na base, estipitados, ramos multífidos, pubescentes. Frutos 5-7 mm diâm., subglobosos, ferrugíneos, denso-pilosos, tricomas lepidotos, mericarpos 3(4), dilatados; sementes 3(4), 2,5-3,5 mm compr., ovais, carunculadas.

Distribuiçấo. É a espécie de mais ampla distribuição na Amazônia brasileira, tendo sido coletada em todos os Estados da região.

Nomes populares. "Coroatâ", "maravuvuia" (Pará); "dima” (Amazonas); sangra-d'água (Mato Grosso).

Material examinado. VENEZUELA. Santa Elena, mata Culta, nos arredores do acampamento da Comissão Demarcadora de Limites, N. A. Rosa \& O. Cardoso 3225 (INPA), 02.IX.1979 (f). BRASIL. Roraima, rodovia BR174, mata alta, Pires \& Dárdano 14.576 (MG), 22.VI.1974 (f); BR-174, estrada Manaus-Caracaraí, I. Cordeiro et al. 68 (MG), 17.I.1985 (fl,fr); Pacaraima, marco BV-8, fronteira Brasil-Venezuela, mata cilar de igarapé, Almeida \& Cordeiro 628 (MG), 19.X.1991 (fr); foothils of serra Tepequem, near igarapé Paparu, forest on terra firme, Prance et al. 4343 (INPA, MG, NY), 12.II.1967 (fl). Amapá, Macapá, estrada do Pedreira, prox. localidade Abacate, ilha de mata, $B . V$. Rabelo et al. 2665 (HAMAB), 29.IV.1984 (fr). Amazonas, rio Negro, rio Jauaperi, estirão Tanacuera, Santos 89 (MG), 24.II.1977 (f); vizinhança de Barcelos, capoeira de terra firme, Fróes 28497 (IAN), 27.IV.1952 (fr); Parque Nacional do Jaú, 0160’39" S, 6135'57” W, E. Rodrigues s/n (MG 158983, SP), 23.XI.1995 (bot); Reserva Florestal Ducke, $02^{\circ} 53^{\prime}$ S, 59058' W, J.R. Nascimento 682 (INPA, MG), 08.XII.1994 (bot, f); Manaus, reserva Ducke, J. Aluísio 325 (INPA, MG), 4.XII.1969 (f); Manaus, reserva Ducke, mata de terra firme, Rodrigues \& Osmarino 5676 (MG), 16.I.1964 (fl); Manaus, rio Negro, Spruce s/n (MG 19559), 1851 (fl, fr); Ibidem, Ule 5387 (MG), II.1901 (f); Barcelos, rio Negro, capoeira alta, Ducke s/n (MG 7104), 9.VI.1905 (fl, fr); distrito agropecuário, fazenda DIMONA, reserva 2303 of WWF/INPA MCS project, M. Pacheco et al. 179 (INPA), 11.II.1989 (f); reserva Ducke, Manaus-Itacoatiara, km 26, Vicentini 430 (INPA, RB), 22.III.1994 (f); Manaus, margem da estrada UFAM, $M$. Santos s/n (INPA 213340), 20.XII.2002 (f); Manaus, UFAM, em frente à biblioteca, M. Santos s/n
(INPA 213341), 20.XII.2002 (f); estrada Manaus-Itacoatiara, Reserva Ducke, Mello \& Ramos s/ $n$ (INPA 57802), 23.VI.1976 (f); Manaus, EMBRAPA/CPAA, M. Skatulla 120 (INPA), 29.XI.1997 (bot, fl); Embrapa-Manaus, M. Skatulla 120 (INPA), 25.XI.1997 (f); Manaus, RAIZ, E. F. Trinta et al. 1490 (INPA), 26.I.1963 (f). Acre, Rio Branco, mata de terra firme, C.A. Cid Ferreira \& B. W. Nelson 2966 (INPA, MG, RB), 19.X.1980 (fr). Pará, lago de Faro, acima de Tanacuera, mata de beira das campinas do Igarapé Infiry, A. Ducke MG 10716 (MG), $13 . I I .1910$ (bot); Belém, Parque Ambiental do Utinga, $1^{\circ} 25^{\circ} 51^{\prime} \mathrm{S}, 48^{\circ} 25^{\circ} 50^{\prime} \mathrm{W}$, Alt: $6 \mathrm{~m}$, mata secundária de terra firme, Cordeiro M.R. s/n (IAN 175451), 21.XII.200 (f); rio Trombetas, Cachoeira Porteira, Ducke s/n (RB 2472, MG), 9.I.1927 (f); Almeirim, mata de terra firme, área Perimetral, N.T. Silva 5464 (MG), 19.I.1981 (f); Largo S. Braz, J. Huber MG 3416 (MG), 24.IV.1903 (fr); Salvaterra, capoeira fechada com boa camada de matéria orgânica em decomposição, A.S.L. da Silva \& C.S. Rosário 2077 (MG), 21.X.1988 (f); Bragança, estrada Grande, mata e capoeira, Ducke s/n (RB 10253, RB), 21.I.1970 (f); Flona Saracá-Taqüera/IBAMA, Porto Trombetas, Oriximiná, Salomão et al. 904 (MG), 16.I.2003 (f); Oriximiná, rio Mapuera, entre as cachoeiras do Patauá e Paraíso Grande, igapó da margem direita, Martinelli 7253 (MG), 27.VI.1980 (f); Paragominas, Itinga do Pará, fazenda Caboré, mata de terra firme, Maciel et al. 439 (MG), 6.XII.1979 (fr); Bragança, campo de baixio, mata secundária, Davidse et al. 18018 (INPA, MG, NY), 8.IV.1980 (f); Faro, mata de terra firme, Ducke s/n (MG 8376), 17.VII.1907 (f); Marajó, Joanes, Salvaterra, Bastos et al. 41 (MG), 16.III.1978 (fr); Marapanim, campo de Matapiquara, ca. $1 \mathrm{~km}$ east of Matapiquara, $73 \mathrm{~km} \mathrm{NNE}$ of Castanhal by roads, elev. $50 \mathrm{~m}$; ca. 056'S 47039'W, C. Davidse et al. s/n (INPA 131592) 5.IV.1980 (fl); Marapanim, Marudazinho, mata baixa, Egler 1370 (MG), 19.I.1960 (fl,fr); Vigia, along road PA-140 to Belém, campina de Caimbé, savanna surrounding forest, Davidse et al. 17650 (MG), $30 . I I I .1980$ (fr); Quatipuru, caminho para o campo Bentivi, Rodrigues 5179 (MG), 11.IV.1963 (fr). Maranháo, Monção, basin of rio Turiaçu, Ka'apor Indian Reserve, terra firme Forest, Balée \& Gely 861 (MG. NY), 10.IV.1985 (fl, fr); São Luís, reserva da CAEMA, igapó, Secco \& Rosa 763 (MG), 4.IV.1988 (fr); São Luís, Itaquihacanga, área da Vale, terra firme, Secco \& Rosa 873 (MG), 27.IV.1998 (fr). Rondônia, Guajará-Mirim, estrada do Palheta, ao pé da serra dos Parecis, terra firme, Silva \& Carreira 329(MG), 28.I.1983 (fr); Mineração Campo Novo, BR-421, a $120 \mathrm{~km}$ de Ariquemes, mata secundária, Vieira et al. 523 (INPA, MG, NY), 18.X.1979 (f); rio Madeira, Prance 8356 (MG), 12.XI.1968 (fl, fr); Porto Velho, Guajará-Mirim, Carreira et al. 329 (INPA, MG), 28.I.1983 (f). Mato Grosso, rodovia BR-80, fazenda Cachimbo, Projeto RADAM, M. R. Cordeiro 1073 (MG, RB), 18.XI.1976 (f). 
Croton matourensis é uma espécie muito variável em relação ao tamanho e aspecto da face abaxial das folhas, que frequentemente apresenta uma tonalidade metálicoferrugínea, dourada ou prateada, devido ao denso indumento de tricomas lepidotos. Esta coloração do indumento, que às vezes é muito acentuada no material seco, fez com que fosse aceita como espécie válida nas identificaçóes feitas em herbários. Ao propor tal espécie, Jablonski (1965) baseou-se especialmente no caráter "styles free at base" (estiletes livres na base). Segundo Loureiro (1968), do ponto de vista da anatomia da madeira, Croton matourensis e C. lanjouwensis praticamente não se diferenciam. Webster et al. (1999) sinonimizaram C. lanjouwensis em $C$. matourensis.

Procedendo-se uma análise acurada das coleçóes de C. matourensis e C. lanjouwensis, e verificando populaçóes naturais em trabalho de campo realizado em Manaus, São Luís (Maranhão) e diversos municípios do Pará, concordouse com Webster (1999) e Secco (2005), constatando-se que trata-se de uma única espécie, $C$. matourensis, sendo todas as amostras analisadas com os estiletes concrescidos na base, formando uma coluna.

A face abaxial das folhas de Croton caryophyllus Benth. apresenta um denso indumento de tricomas lepidotos, assim como em C. matourensis. Além disso, nos demais caracteres morfológicos, tais como flores estaminadas com pétalas estreito-lanceoladas e11 estames; flores pistiladas com lobos do cálice fendidos apenas no ápice e ovário trígono, com estilete estipitado, C. caryophyllus assemelha-se bastante com C. matourensis, daí ter sido proposta sua sinonimização.

\section{AGRADECIMENTOS}

Ao CNPq, pela bolsa de mestrado concedida ao autor, e bolsa de produtividade em pesquisa (processo n. 302.036/2004-0) concedida ao coautor; ao Museu Paraense Emilio Goeldi, pelas facilidades concedidas para a realização deste trabalho; aos curadores dos herbários BM, F, G, GH, IAN, INPA, K, MG, MO, NY, RB, U e W, pelo empréstimo das coleçóes analisadas; ao Dr. Paul E. Berry, da University of Michigan, pela cessão de imagens de tipos; à Dra. Ely Simone C. Gurgel, pelo auxílio na formatação das figuras; à Dra. Anna-Luiza Benkendorf, pela revisão do texto em inglês; ao Dr. Antônio Carlos Webber, pelo paciente acompanhamento editorial do manuscrito, e aos referees, pelas sugestóes apresentadas ao texto.

\section{BIBLIOGRAFIA CITADA}

Barroso, G.M. 1991. Systematics of Brazilian Angiosperm. Editora Universidade Federal de Viçosa, Viçosa, Minas Gerais, v. 2. 377 pp. (in Portuguese).
Cordeiro, I. 1992. Flora of "Serra do Cipó". Minas Gerais. Euphorbiaceae. Boletim de Botânica, Universidade de São Paulo, 13: 169-217. (in Portuguese, with abstract in English).

Croizat, L. 1944. Additions to the genus Croton in South America. Darwiniana, 6(3): 443-468.

Govaerts, R.; Frodin, D.G.; Radcliffe-Smith, A. 2000. World Chechklist and bibliography of Euphorbiaceae (with Pandaceae) 1-4. The Royal Botanic Gardens, Kew, Great Britain.

Grenand, P.; Moretti, C.; Jacquemin, H. ; Prévost, M-F. 2004. The traditional pharmacopoeia in Guyana. IRD Editions, Paris. 816 pp. (in French).

Holmgren, P.K.; Holmgren, N.H.; Barnett, L.C. (eds.). 1990. Index Herbariorum.. Part I. The herbaria of the world, 8a. ed. The New York Botanical Garden, New York, USA. 452pp.

Jablonski, E. 1965. Euphorbiaceae. In: Maguire, B. (ed.). Botany of the Guayana Highlands- part VI. Memories of the New York Botanical Garden, 12: 150-178.

Linnaeus, C. 1753. Species Plantarum, exihibentes Plantas Rite Cognatas, ad Geneva Relatas. vol. 2. Stockholm: Laurentii Salvil, v. $2.1004 \mathrm{pp}$.

Loureiro, A. A. 1968. Contribuition to the anatomical study of Croton lanjouwensis (Müll. Arg) Jabl. and Croton matourensis Aublet (Euphorbiaceae). INPA, Publ. n. 24, Sér. Botânica: 3-16. (in Portuguese, with abstract in English).

Macbride, J.F. 1951. Flora of Peru- Euphorbiaceae. Field Museum of Natural History, Botany series, 13, 3A(1): 3-200.

Müller, J. 1865. Euphorbiaceae. Linnaea, 34: 1-224.

Müller, J. 1873. Euphorbiaceae. Euphorbiaceae. Croton. In: Martius, C.F.P \& Eichler, A.G. (Eds.). Flora brasiliensis, 11(2): 1-292, tab. $1-42$.

Murillo-A., J. 1999. Composicion and distribution of the genus Croton in Colombia, with four new species. Caldasia, 21(2): 141-166. (in Spanish, with abstract in English).

Pieters, L. 1998. The "sangre de drago", a traditional South America drug. Biological actives principles. Ediciones Abya-Yala, Quito, Ecuador. 209 pp. (in Spanish, with abstract in English).

Schultes, R.E. 1987. Members of Euphorbiaceae in primitive and advanced societies. Botanical Journal of Linnean Society, 94: 79-95.

Secco, R.S. 1992. Notes on the vines of the genus Croton L. (Euphobiaceae). Boletim do Museu Paraense Emilio Goeldi, série Botânica, 8(2): 265-281. (in Portuguese, with abstract in English).

Secco, R.S.; Berry, P.E.; Rosa, N.A. 2001. Croton trombetensis and Croton diasii: two new Euphorbiaceae from Amazonian Brazil. Novon, 11: 119-123.

Secco, R. S.; Cordeiro, I. 2002. Notes on the first record of Croton urucurana Baill. (Euphorbiaceae) in Amazonia. Boletim Museu Paraense Emilio Goeldi, série Botânica, 18(1): 195-201. (in Portuguese, with abstract in English).

Secco, R. S. 2004. Croton dissectistipulatus, a new species of Euphorbiaceae from Amazonian Brazil. Brittonia, 56(4): 353356. 
Secco, R.S. 2005. Flora of Reserva Ducke, Amazonas, Brasil: Euphorbiaceae - Parte I. Rodriguésia, 56(86): 143-168. (in Portuguese, with abstract in English).

Secco, 2008. Synopsis of Brazilian Amazonia species of Croton L. (Euphorbiaceae): a taxonomic essay. Museu Paraense Emilio Goeldi (Coleção Adolfo Ducke), Belém, Pará. 169pp. (in Portuguese, with abstract in English).

Secco, R.S. 2009. A new species de Croton sect. Geiseleria (Euphorbiaceae) from Eastern Amazonian, Brazil. Revista Brasileira de Botânica, 32(2): 249-252. (in Portuguese, with abstract in English).

Secco, R.S.; Berry, P.E.; Rosário, C.S. 2005. A new species of Croton sect. Luntia (Euphorbiaceae) from Western Amazonian, Brazil. Novon, 15(4): 583-585.
Webster, G.L. 1993. A provisional synopsis of the section of the genus Croton (Euphorbiaceae). Taxon, 42: 793-823.

Webster, G.L. 1994. Classification of the Euphorbiaceae. Annals of Missouri Botanical Garden, 81(1): 3-32.

Webster, G. L.; Berry, P.E.; Ambruster, W.S.; Esser, H-J.; Gillespie, L.J.; Hayden, W.J.; Levin, G.A.; Secco, R.S; Heald, S.V. 1999. Euphorbiaceae. In: Berry, P.E.; Yatskievych, K.; Holst, B.K. (Eds.), Flora of the Venezuelan Guayana. v. 5. Missouri Botanical Garden Press, St. Louis, USA. p. 72-228.

Recebido em 15/02/2008

Aceito em 10/11/2009 